\title{
Screening of CHP Potential at Federal Sites in Select Regions of the U.S.
}

\author{
Subcontract \#4000008602
}

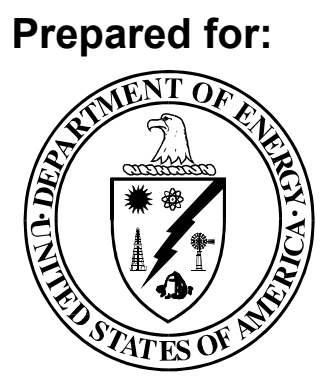

\author{
The Department of Energy \\ Oak Ridge National \\ Laboratories \\ Federal Energy Management \\ Program \\ Oak Ridge, TN
}

Prepared by:

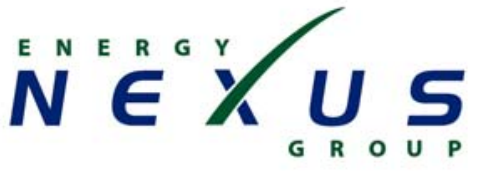
Energy Nexus Group
Carlsbad, CA 


\section{Table Of Contents}

Table Of Contents............................................................................................................................................ $i$

Acknowledgements ........................................................................................................................................ ii

Executive Summary ........................................................................................................................... 3

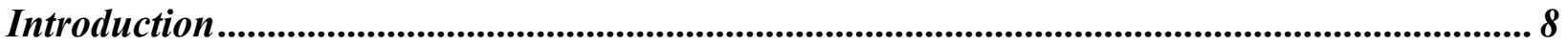

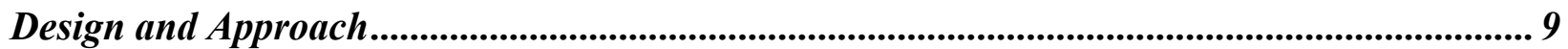

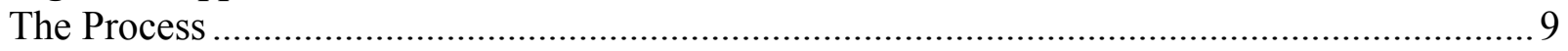

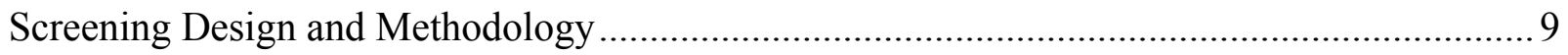

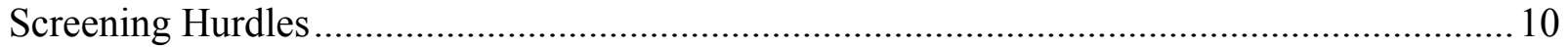

Positive Initial Indicators ………………...................................................................... 11

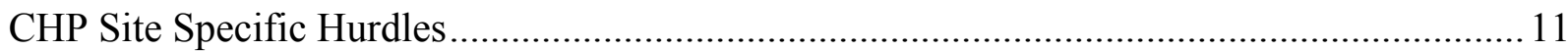

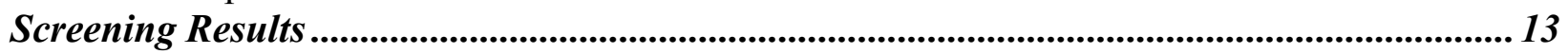

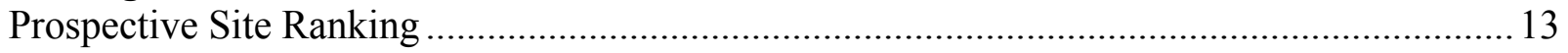

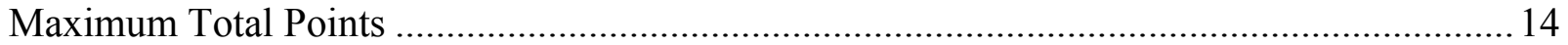

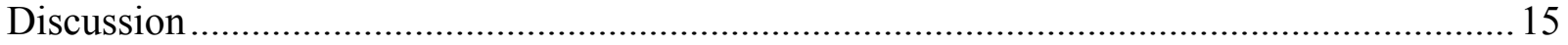

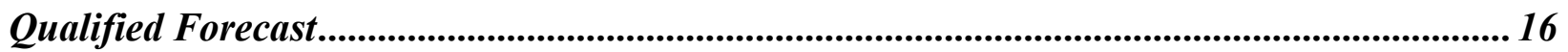

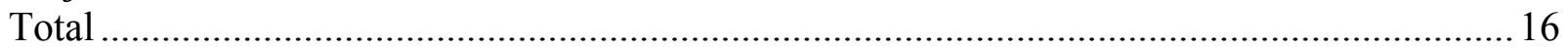

Current Energy Costs Present Near Term CHP Opportunities............................................. 17

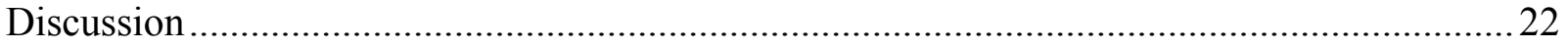

Conclusions and Recommendations..................................................................................... 22

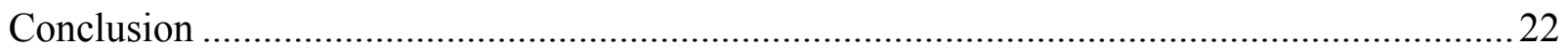

Appendix A - CHP Background................................................................................................... 26

The Technical Promise of CHP ................................................................................... 27

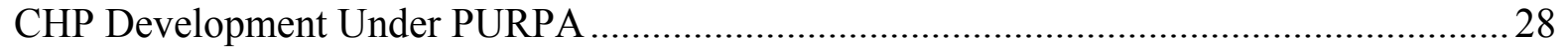

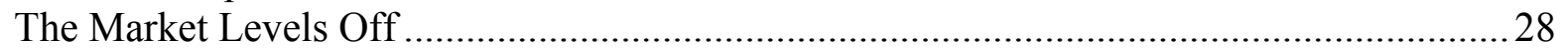

Opportunities for CHP in a Restructured Electricity Market ................................................22

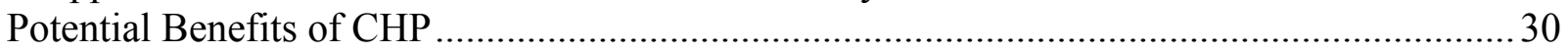

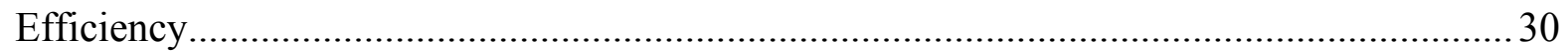

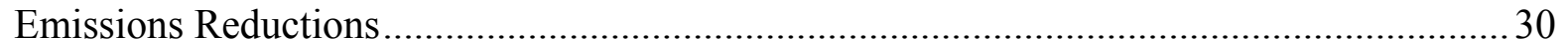

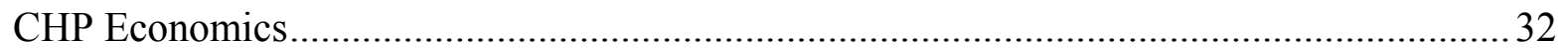

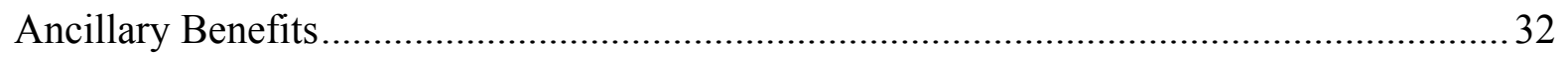

Market Barriers ............................................................................................................................. 33

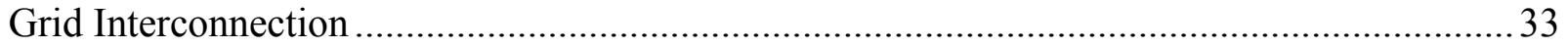

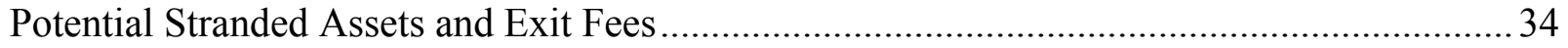

Standby/Back-up Charges.................................................................................................. 34

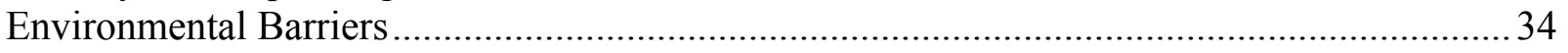

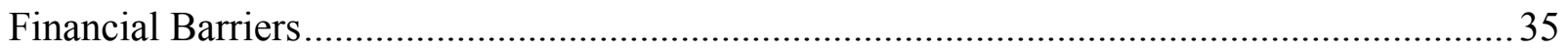

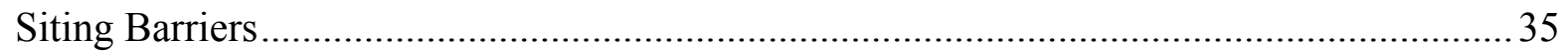

Appendix B - Data Collection........................................................................................................ 37

Appendix C-Excerpt Federal CHP Resource Guide ....................................................................... 41

Near Term CHP Projects ................................................................................................... 41

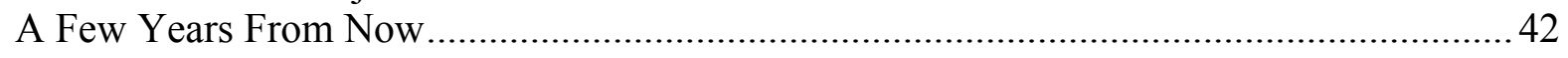

Long-term Prospects (5 or more years) ……………........................................................ 42

Appendix D - Site Log............................................................................................................................. 43

Appendix E - QF CHP Plants that may serve Federal Facilities.................................................... 44

Appendix F: Feasibility Analysis for CHP............................................................................................ 45 


\section{ACKNOWLEDGEMENTS}

The Energy Nexus Group, a wholly owned subsidiary of Onsite Energy Corporation, wishes to acknowledge and thank Patrick J. Hughes and Keith Kline of the Oak Ridge National Labs for their continued support and direction of this work. Appreciation is extended to the Department of Energy's Federal Energy Management Program Managers (Beth Shearer, Director), Regional DOE Program Managers, staff whose work supported this effort, and to the individual Federal Facility Managers who participated in the screenings. The authors are also grateful to our own Kathy Gallagher, who assisted in editing and formatting this document.

Note While this report was prepared with support from the Department of Energy Federal Energy Management Program the Oak Ridge National Labs (ORNL), the views and opinions expressed herein are the authors and do not necessarily reflect those of the U.S. government or any employee thereof. 


\section{EXECUTIVE SUMMARY}

Combined Cooling Heat and Power (CHP) is a master term for onsite power generation technologies that sequentially produce electrical or mechanical energy and useful thermal energy. Some form of CHP has existed for more than 100 years and it is now achieving a greater level of acceptance due to an increasing need for reliable power service and energy cost management. Capturing and using the heat produced as a byproduct of generating electricity from fuel sources increases the usable energy that can be obtained from the original fuel source. CHP technologies have the potential to reduce energy consumption through increased efficiency - decreasing energy bills as well as pollution. The EPA recognizes $\mathrm{CHP}$ as a potent climate change mitigation measure.

The U.S. Department of Energy (D.O.E.) Federal Energy Management Program (FEMP) is assisting Federal agencies to realize their energy efficiency goals. CHP is an efficiency measure that is receiving growing attention because of its sizable potential to provide efficiency, environmental, and reliability benefits. CHP therefore benefits the host facility, the electric infrastructure, and the U.S. society as a whole.

This report and study seeks to make a preliminary inquiry into near term CHP opportunities for federal facilities in selected U.S. regions. It offers to help focus the attention of policy makers and energy facility managers on good candidate facilities for CHP. First, a ranked list of high potential individual sites is identified. Then, several classes of federal facilities are identified for the multiple opportunities they offer as a class. Recommendations are then offered for appropriate next steps for the evaluation and cost effective implementation of CHP.

This study was designed to ultimately rank federal facilities in terms of their potential to take advantage of CHP economic and external savings in the near term. In order to best serve the purposes of this study, projections have been expressed in terms of sizing CHP to thermal and electrical estimates. The table below is a summary of findings of CHP potential for those federal facilities that chose to participate in the screening process.

The study focused on three U.S. regions: California, Texas, and New York / New England. All federal facilities in these three regions with reported building space greater than 100,000 square feet were initial targets to contact and offer CHP screening services. Ranking criteria were developed to screen sites for near term CHP potential. The potential site list was pared down for a variety of reasons including site- specific and agency wide decisions not to participate, desk audit assessments, and untraceable contact information. The results are based upon the voluntary participation of those sites we were able to contact, so they reflect a fraction of the total potential CHP opportunities at federal government facilities. 
Table ES-1. Regional Ranking of CHP Potential

\begin{tabular}{lccc} 
CA Agency Site ID \# & CHP Potential & $\begin{array}{c}\text { Size to Electrical } \\
\text { Load (MW) }\end{array}$ & $\begin{array}{c}\text { Size to Thermal } \\
\text { Load (MW) }\end{array}$ \\
\hline 001 & High & 50 & 10 \\
002 & High & 2.5 & 5 \\
003 & High & 70 & 70 \\
004 & High & 20 & 20 \\
005 & High & 1 & 1 \\
006 & High & 2 & 2 \\
007 & Medium & 15 & 15 \\
008 & Medium & 12 & 1.5 \\
009 & Medium & 15 & 15 \\
010 & Medium & 10 & 1 \\
011 & Medium & 2 & 2 \\
012 & Medium & 41 & 1.5 \\
013 & Medium & 11 & 11 \\
014 & Medium & 19 & 19 \\
015 & Low & 3 & 1.5 \\
Total: & & $\mathbf{2 7 3 . 5}$ & $\mathbf{1 7 5 . 5}$ \\
& & & \\
NY I New England & CHP Potential & Size to Electrical & Size to Thermal \\
Agency Site ID \# & & Load (MW) & Load (MW) \\
\hline 016 & High & 40 & 4 \\
017 & High & 3 & 3 \\
018 & Medium & 50 & 50 \\
019 & Medium & 1 & 1 \\
020 & Medium & 1.3 & 1 \\
021 & Medium & 3 & 3 \\
022 & Medium & 2.7 & 2.7 \\
023 & Medium & 1 & $\mathbf{6 5 . 7}$ \\
Total: & & &
\end{tabular}


Table ES-1. Regional Ranking of CHP Potential (cont.)

\begin{tabular}{lccc}
$\begin{array}{l}\text { TX Agency Site } \\
\text { ID \# }\end{array}$ & CHP Potential & $\begin{array}{c}\text { Size to Electrical } \\
\text { Load (MW) }\end{array}$ & $\begin{array}{c}\text { Size to Thermal } \\
\text { Load (MW) }\end{array}$ \\
\hline 024 & High & 1.6 & 1 \\
025 & High & 32 & 6 \\
026 & High & 2.3 & 2 \\
027 & Medium & 14 & 3 \\
028 & Medium & 37 & 2 \\
029 & Medium & 30 & 6 \\
030 & Medium & 30 & 0 \\
031 & Low & 2 & 2 \\
032 & Low & 1.3 & 1 \\
033 & Low & 1.7 & 2 \\
Total: & & $\mathbf{1 5 1 . 9}$ & $\mathbf{2 5}$
\end{tabular}

A discussion of the findings in this table and the process utilized to reach these findings is contained in the National Ranking section.

Recent electricity and regulatory changes are creating renewed optimism for CHP in Federal facilities. Applications that scored well on the ranking criteria include large federal campuses (labs and military bases) with central heating and cooling plants, hospitals, and US Postal distribution centers.

CHP faces additional challenges to Federal Facilities and their ESCO Alliances than more traditional efficiency measures. Such hurdles include the relatively high capital cost of CHP, local utility rates and practices, environmental permitting, electric and thermal load matching, uncertainty over future electric and gas rates, and concern over O\&M requirements.

The Table ES-2 illustrates the impact on various national key parameters if only the projects envisioned in Table ES-1 were installed. It is clear from this study that inertia and lack of knowledge were causes leading to the current downtrend of combined heat and power facilities in the federal government. It is therefore recommended that FEMP provide CHP resource support to targeted facilities and affiliated ESCO's. Such support would certainly include benchmarking CHP feasibility studies for the highly ranked large federal campuses and for representative Federal hospitals and U.S. Postal Service distribution centers. A robust CHP outreach program is also urged to enable proactive Federal agencies and facility managers to learn more about CHP and how to conduct a preliminary evaluation. 
Table ES-2. The Relevance of CHP Potential

Size to

Thermal

Load

National Aggregate Potential Capacity (MW)

372

Total Annual Energy Saved (billions of cubic feet of natural gas equivalent)

Number of American Homes Served by Total Annual Energy Saved

111,000

Number of American Cars Needed Off the Highway to Equal Resultant

105,000 $\mathrm{CO}_{2}$ Emission Reduction

Number of American Cars Needed Off the Highway to Equal Resultant

$\mathrm{NO}_{\mathrm{x}}$ Emission Reduction

$1,040,000$

Annual Reduction in Federal Government's Energy Bill

\$57 Million

Table ES-3. Summary of Results of Survey

\begin{tabular}{|l|c|c|c|c|}
\hline & California & Texas & New England & Total \\
\hline \hline Sites under initial review (1) & 164 & 134 & 197 & 495 \\
\hline $\begin{array}{l}\text { Sites eliminated/not } \\
\text { contacted (2) }\end{array}$ & 91 & 104 & 145 & 340 \\
\hline $\begin{array}{l}\text { Sites w/data indicating no } \\
\text { potential (4) }\end{array}$ & 58 & 20 & 45 & 123 \\
\hline $\begin{array}{l}\text { Sites w/data indicating CHP } \\
\text { Potential (5) }\end{array}$ & 15 & 10 & 7 & 32 \\
\hline $\begin{array}{l}\text { MW CHP potential sized to } \\
\text { thermal at screening sites (6) }\end{array}$ & 176 & 25 & 66 & 267 \\
\hline $\begin{array}{l}\text { MW CHP potential at similar } \\
\text { sites w/o site data (7) }\end{array}$ & 55 & - & 50 & 105 \\
\hline \hline
\end{tabular}




\begin{tabular}{|l|l|l|l|l|}
$\begin{array}{l}\text { Total estimated CHP } \\
\text { potential based on screening }\end{array}$ & 231 & 25 & 116 & 372 \\
\hline & & & & \\
\hline
\end{tabular}

Table ES-3. Footnotes

1. Initial site list for review is based on the FEMP Geographic Information System (GIS) database of federal facilities with total building area greater than 100,000 sq.ft.

2. Sites eliminated without consulting energy manager due to closures, large number of small buildings, relatively small amount of conditioned space in total area, or inability to identify contact person.

3. Sites where data is sufficient to conclude there is little potential to do a CHP project at present due to future uncertainty over mission/location, lack of infrastructure (central plant/large mechanical room), decentralizing away from district systems, no interest in participating, etc.

4. Sites with data and an interest in CHP and at least one central plant or mechanical room at site.

5. MW of CHP potential estimated based upon reported thermal loads. Total CHP potential sized to electric loads was estimated at $278 \mathrm{MW}$.

6. Several VA hospitals and large USPS facilities were unable to provide site-specific data, but they appear to offer strong potential based on similar sites with data.

\section{Recommendations Summary:}

The following recommendations were offered in this report: (See Conclusions and recommendations section for detail)
1) Outreach
2) Federal Advocacy
3) Approach the Large Ranked Facilities and their ESCO's
4) Obtain region specific energy cost data
5) Approach the ARMY and the NAVY regarding their hospitals.
6) Approach the Veterans Administration
7) Approach the US Postal Service
8) and continued screening in this and other regions of the U.S. 


\section{INTRODUCTION}

High-energy costs and reduced reliability are affecting federal balance sheets and agencies' abilities to fulfill their mission in California with potential to spill over to other regions of the USA. High California wholesale power market prices have bled through to commercial and industrial retail customers in the San Diego area, other customers there and elsewhere in the state to a lesser extent, and to many retail customers throughout the western grid inter-connection region. Drought, generation capacity constraints, planned but uncoordinated generator maintenance, and unplanned generator maintenance have conspired to result in a series of winter Stage 2 and 3 power shortage alerts and the next few years, especially summers of 2001 and 2002, are expected to be difficult. Other regions may become susceptible to similar problems with supply and reliability.

The DOE Federal Energy Management Program (FEMP) is collaborating with other federal, state and local institutions and private parties to respond to the need to lower energy costs, demand, and consumption. FEMP's interest is to assist federal agencies in sustaining their missions in the short term while continuing to make progress toward their energy/water use reduction goals in the mid- and long-term. It is believed that short and mid-term investments in federal energy projects may help ease the power generation capacity constraints, and contribute to the objectives of reduced emissions and lower energy bills through more efficient energy systems.

FEMP is working with public and private partners to promote the use of distributed energy resources including Combined Cooling Heat and Power (CCHP), Combined Heat and Power (CHP) systems. The conversion of fuels to electricity results in large quantities of waste heat as a by-product. Traditional power plants simply reject this heat to the environment. CHP systems decentralize the power generation to locations near facilities having thermal requirements that can be met with the waste heat. Prime candidates for large CHP systems are federal sites having central boiler/chiller plants and district heating/cooling systems that are in good repair. Smaller CHP systems (microturbines) are judged to be more costly and less able to significantly contribute to easing generation capacity constraints immediately. For additional background on $\mathrm{CHP}$, see Appendix $A$

Energy Nexus Group (as Onsite) was retained by Oak Ridge National Laboratory to help relevant federal agencies and facilities to develop site-specific data on the potential benefits, including electric summer peak demand reductions, available by deploying CHP at central plants. The scope is all federal facilities with central plants or an interest in onsite power $(>1 \mathrm{MW})$ in California, Texas and New England. 


\section{DESIGN AND APPROACH}

\section{The Process}

To conceptualize these barriers and attempt to avoid the pitfalls which would encumber the implementation of combined heat and power systems in federal facilities, the Department of Energy's Federal Energy Management Program at Oak Ridge National Labs retained Onsite Energy Corporation to assess the federal sector Combined Heat and Power potential in three regions of the US. The regions studied include California, New England including New York, and Texas. To accomplish the goals Onsite designed a project with several elements.

Intention and direction was established through the study of previous federal cogeneration efforts. A screening data collection format was created to define CHP potential on a rudimentary level, without getting into market level technical assessment of potential. The scope of federal facilities studied was defined as those facilities with greater than 100,000 square feet of floor space as reported through the FEMP Tracks database provided by ORNL. Data collection from federal facilities with central plants was initiated in mid April, and responses to this effort began to arrive in early May. Those federal facilities without central plants were not included in this data collection effort, and those facilities, which were possible candidates, were screened in a phone dialog to determine the presence of greater than 100,000 square feet of building space, presence of a central plant and a consumption of greater than one megawatt.

\section{Screening Design and Methodology}

The Onsite team was contracted to pursue multiple lines of inquiry in order to arrive at a comprehensive list of federal facilities that have an interest or potential in CHP of greater than $1 \mathrm{MW}$. The data requested from federal facilities includes agency site name and full address, agency site contact (phone, email, fax), date that data was last revised, central plant name, brief narrative description of central plant, central plant equipment data (type, size, age, number of units, fuel - primary and backup, present annual energy use and costs, O\&M history and state of repair, annual and peak thermal loads - heating, cooling, process), state of repair and age of district heating/cooling systems, agency site mission stability (growing, secure, in jeopardy, etc), past experience with DSM projects and how they were implemented, existing CHP generating capacity if any and data on its performance, level of interest in CHP, status of any studies or shelf projects relevant to CHP and corresponding potential CHP generating capacity, perceived and real obstacles to CHP installation (including market barriers), any special opportunities or incentives for CHP installation at the site. Most of the Federal Facilities were not able to supply all of this data in one sitting, and in many cases the data was gathered to the extent possible on a per facility basis. 
A screening data collection mechanism was created using the scope of work and a scoring mechanism conceived by Onsite Energy. The original intent of this data collection format was to get some quick answers about federal facilities energy management and energy sources. Emphasis was placed upon brevity and efficiency. The complexities of determining combined heat and power potential from cursory investigation formats stymied attempts to simplify the data collection format. The final draft screening was three-pages long with several cutoff points. The data collection format is included in its entirety in Appendix B.

The first four questions in the data collection form were the primary cutoff points in a telephone interview format. The first question of "What is the electrical load of the facility (avg. MW), and is this load greater than one MW?" was the first cutoff point in the data gathering. If the electrical load met the proper criteria, a second inquiry about the facility's production of steam, hot water, and or chilled water was ventured, with continued data collection efforts contingent upon the presence of a central plant or central loop. The third and forth questions that determined if the gatherer should continue studying a site for CHP potential were focused upon the electricity rates that the facility paid and the reliability of their electrical supply.

\section{Screening Hurdles}

At the time of this effort, California's energy sector was in crisis and relevant federal contacts were preoccupied and difficult to reach. The implications of the energy markets affect upon federal facility energy managers was quickly recognized in California and as a result the burden of screening data gathering shifted to contacting federal facility managers and faxing or e-mailing the data gathering format, so that the concerned personnel would have the appropriate time necessary to respond to the query. The initial contact with facility energy managers took a greater amount of time than initially anticipated.

The biggest problem experienced in the process of gathering information occurred in efforts to find the appropriate point of contact for the site. The FEMPTRACKS contact listing, where one was provided, was seldom current. It was very difficult to sort out the status of D.O.D. bases that were in the process of closing or had already been transferred to other agencies, as in many cases the details of these transfers were not yet completed. Onsite tried to go through the federal agencies to get a line on closed facilities, however as there is less "corporate memory" of closed facilities, given that many of the personnel have moved on, this was not productive. The Onsite team found that it takes two or three times longer to qualify a site as downsized or closed as it does to contact an existing site.

In California, there seems to be a major shift from individual agencies operating facilities to operation by GSA. The federal courts system is in the middle of a 5-year construction program that is adding 61 new courthouses across the country. Initial investigations led data gatherers to believe prisons have greatly expanded as well. Some of these new facilities were more difficult to contact, as the contact information has not yet been entered into accessible databases. 
The most productive technique for locating facility managers and conducting screening included combinations of Internet research, cold-calling a facility's public affairs agency, and tracking facilities through databases. It is possible that agencies could respond to such inquiries through agency wide approaches, but this would require a much longer time frame with much broader involvement and scope. The better approach may be to break the entire target category down into segments of 50 to 80 sites and concentrate efforts on size groupings with similar interests and structural configurations.

\section{Positive Initial Indicators}

The first positive indication of a possible combined heat and power application is the facility's average load. Sales of electric power off-site are problematic and generally not a significant contributor to site economics. It is better for the generated power to be used to offset the facility's purchase of power from the local electricity provider.

For CHP to be cost effective, it is next useful if there is a large central plant to use the thermal energy made available from the generation of power. The first choice should always be to use the heat directly thus avoiding the purchase of fuel. Process heating makes this possible year round for many industrial CHP applications. The challenge for federal facilities is that most of the opportunities do not have process heating needs. Site requirements for thermal energy are for heating in the winter and for absorption cooling in the summer.

Using thermal energy made available from the generation of power in absorption chilling machines to produce chilled water, though not generally as profitable as the direct use of the heat, can offer important contributions to the economics of CHP. Absorbers are large and therefore their application is also aided by the existence of central plants.

The most efficient combined heat and power plants are those that use all of the heat made available from the prime mover. The most efficient CHP facilities are therefore sized to produce no more heat than can be used at the site. It is clear then that facilities with large amounts of conditioned space will lead to the largest CHP facilities. Square footage would then be an additional prime indicator for success.

\section{CHP Site Specific Hurdles}

In addition to the general indicators of virtue described above, there are several hurdles and potential showstoppers that can be strewn in the path of successful CHP projects. These issues were raised by those facilities that currently combine heat and power production, as well as through Onsite's past experience in CHP applications. The following issues were ones that Onsite Energy attempted to assess through this screening:

Electric Rates - For CHP to have the best economics, electric rates need to be high, predictable and significantly avoidable. It is clear that the western region is suffering a "sea change" with regards to electric rates. A shortage of generating capacity led to extraordinary energy market prices. Classic economic theory indicates that these prices will moderate and the market price should settle on the replacement cost of power. 
Replacement cost of power would be the delivered price of power from a new combined cycle plant. In general, this price should be high enough to justify the long-term economics of efficient CHP. Local problems can arise however if the local electric utility is allowed to charge un-justifiably high standby rates or demand charges that make a large portion of a facility's electric costs unavoidable through the use of CHP. A facility's average cost of power is not necessarily a good indicator of CHP economics.

Natural Gas Rates - Natural gas is the most likely fuel to be used in most federal CHP applications. As the major cost component of CHP, it is clear that lower prices help the economics. What were particularly puzzling in this study were the high prices being reported by many large facilities. Though this could be explained in California by recent transmission constraints at the California/Arizona border, why large federal facilities in Texas were paying prices reported to be almost twice that of the prevailing wholesale price is a subject of concern.

Air Quality Requirements - Emission requirements can complicate the application of CHP. For combustion turbines, selective catalytic reduction will likely be required. In the regions examined in this study, this is costly and can be very tough on smaller projects $(<3$ $\mathrm{mw}$ ). For reciprocating engines, lean burn technology (with its attendant prime mover efficiency) is sufficient in large parts of the country. However, in California, requirements are likely to require the use of less efficient rich burn technology with three way catalysts and air/fuel ratio controllers. 


\section{SCREENING RESULTS PROSPECTIVE SITE RANKING}

This is a ranking of projects for which data was submitted. It is by no means exhaustive. The scoring system used to calculate the "Total Ranking Score" is described on Table 2.

Table1. National Ranking of CHP Potential

\begin{tabular}{|c|c|c|c|c|}
\hline Agency Site ID \# & $\begin{array}{l}\text { Total Ranking } \\
\text { score }\end{array}$ & $\begin{array}{c}\text { Size to Electrical Load } \\
\text { Size }(\mathrm{mw})\end{array}$ & $\begin{array}{c}\text { Size to Thermal Load } \\
\text { Size }(\mathrm{mw})\end{array}$ & Region \\
\hline 001 & 83 & 50 & 10 & CA \\
\hline 002 & 80 & 2.5 & 5 & CA \\
\hline 003 & 79 & 70 & 70 & $\mathrm{CA}$ \\
\hline 016 & 74 & 40 & 4 & NE \\
\hline 005 & 73 & 1 & 1 & $\mathrm{CA}$ \\
\hline 024 & 71 & 1.6 & 1 & TX \\
\hline 017 & 71 & 3 & 3 & $\mathrm{NE}$ \\
\hline 025 & 70 & 32 & 6 & $\mathrm{TX}$ \\
\hline 004 & 66 & 20 & 20 & $\mathrm{CA}$ \\
\hline 026 & 65 & 2.3 & 2 & $\mathrm{TX}$ \\
\hline 006 & 65 & 2 & 2 & $\mathrm{CA}$ \\
\hline 007 & 60 & 15 & 15 & $\mathrm{CA}$ \\
\hline 008 & 59 & 12 & 1.5 & CA \\
\hline 009 & 59 & 15 & 15 & $\mathrm{CA}$ \\
\hline 027 & 59 & 14 & 3 & $\mathrm{TX}$ \\
\hline 020 & 58 & 1 & 1 & $\mathrm{NE}$ \\
\hline 018 & 58 & 50 & 50 & $\mathrm{NE}$ \\
\hline 019 & 58 & 1 & 1 & $\mathrm{NE}$ \\
\hline 021 & 58 & 3 & 3 & NE \\
\hline 023 & 58 & 1 & 1 & $\mathrm{NE}$ \\
\hline 022 & 56 & 2.7 & 2.7 & $\mathrm{NE}$ \\
\hline 010 & 54 & 10 & 1 & CA \\
\hline 011 & 54 & 2 & 2 & $\mathrm{CA}$ \\
\hline 012 & 51 & 41 & 1.5 & $\mathrm{CA}$ \\
\hline 013 & 51 & 11 & 11 & $\mathrm{CA}$ \\
\hline 028 & 49 & 37 & 2 & TX \\
\hline 029 & 48 & 30 & 6 & TX \\
\hline 030 & 45 & 30 & 0 & TX \\
\hline 014 & 41 & 19 & 19 & $\mathrm{CA}$ \\
\hline 031 & 32 & 2 & 2 & $\mathrm{TX}$ \\
\hline 032 & 32 & 1.3 & 1 & $\mathrm{TX}$ \\
\hline 033 & 32 & 1.7 & 2 & $\mathrm{TX}$ \\
\hline 015 & 28 & 3 & 1.5 & $\mathrm{CA}$ \\
\hline \multicolumn{2}{|c|}{ Totals: } & 529.4 & 268.2 & \\
\hline
\end{tabular}


Table 2. Scoring System

\begin{tabular}{|c|c|c|}
\hline Criteria & Description & $\begin{array}{c}\text { Maximum } \\
\text { Possible } \\
\text { Points } \\
\end{array}$ \\
\hline Electric Load & $\begin{array}{l}\text { The economics of CHP are enhanced through the economies of } \\
\text { scale. Electric load is the first indicator for the plant's potential } \\
\text { size }\end{array}$ & 12 \\
\hline Central Plant & $\begin{array}{l}\text { A central plant indicates the prior existence of a distribution } \\
\text { system for the delivery of thermal energy. }\end{array}$ & 12 \\
\hline Electric Rate & $\begin{array}{l}\text { The avoidable electric rate is the primary source of energy cost } \\
\text { savings. }\end{array}$ & 12 \\
\hline Grid Reliability & $\begin{array}{l}\text { If CHP can provide relief from grid reliability problems, its } \\
\text { value is enhanced. }\end{array}$ & 4 \\
\hline Daily Load Variation & Flat daily loads improve the economics of CHP & 4 \\
\hline $\begin{array}{l}\text { Un-met Need for } \\
\text { Standby Power }\end{array}$ & $\begin{array}{l}\text { If the purchase of electric standby equipment was envisioned, } \\
\text { perhaps a CHP can provide the needed redundancy to the grid } \\
\text { instead. }\end{array}$ & 2 \\
\hline Seasonal Load Variation & Flat seasonal loads improve the economics of CHP. & 3 \\
\hline Fuel Cost & $\begin{array}{l}\text { The cost of fuel is the primary operating cost of a CHP plant. } \\
\text { Lower cost fuel is good. }\end{array}$ & 4 \\
\hline $\begin{array}{l}\text { Condition of Existing } \\
\text { Thermal Equipment }\end{array}$ & $\begin{array}{l}\text { Boiler or electric chillers in need of replacement can be } \\
\text { replaced with waste heat boilers and absorption chillers that } \\
\text { accommodate CHP. }\end{array}$ & 2 \\
\hline Thermal Load & $\begin{array}{l}\text { The fuel saved in providing heat from a CHP system to a } \\
\text { thermal load is the second major source of energy savings for } \\
\text { CHP and provides for its intrinsic efficiency. }\end{array}$ & 5 \\
\hline Air Quality Permits & $\begin{array}{l}\text { Difficult air quality standards pose additional first costs and } \\
\text { operating costs on CHP. }\end{array}$ & 4 \\
\hline $\begin{array}{l}\text { Presence of a Licensed } \\
\text { Engineer }\end{array}$ & $\begin{array}{l}\text { A central plant that is already adequately staffed removes the } \\
\text { need for additional staff to operate and maintain the CHP } \\
\text { facility. }\end{array}$ & 4 \\
\hline $\begin{array}{l}\text { Existing CHP Studies or } \\
\text { Plans }\end{array}$ & $\begin{array}{l}\text { This is an indicator of institutional interest in CHP and it could } \\
\text { also shorten the time to eventual CHP installation. }\end{array}$ & 5 \\
\hline Mission Stability & $\begin{array}{l}\text { Indicates that the facility will be around for a sufficient period } \\
\text { of time to realize the full potential of an installed CHP plant. }\end{array}$ & 12 \\
\hline $\begin{array}{l}\text { Progress on Energy } \\
\text { Efficiency Measures }\end{array}$ & $\begin{array}{l}\text { It is generally most cost effective to complete all of the least } \\
\text { costly efficiency measures before embarking on plans to install } \\
\text { CHP. }\end{array}$ & 3 \\
\hline $\begin{array}{l}\text { Existence of an Alliance } \\
\text { with an ESCO }\end{array}$ & $\begin{array}{l}\text { Generally, but not always, the existence of an ESCO on site } \\
\text { provides an extra measure of knowledge and perhaps the source } \\
\text { of capital for the installation of CHP. }\end{array}$ & 2 \\
\hline \multirow[t]{2}{*}{$\begin{array}{l}\text { Willingness to } \\
\text { Cooperate with FEMP } \\
\text { on a cogeneration study. }\end{array}$} & $\begin{array}{l}\text { Interest is always an important indicator of potential success } \\
\text { regarding the installation of CHP. }\end{array}$ & 10 \\
\hline & Maximum Total Points & 100 \\
\hline
\end{tabular}




\section{Discussion}

There are six facilities for which data was insufficient for points to be awarded in some categories. Therefore the scoring for these facilities could be deceptively low. Usually the toughest data to obtain was the facilities thermal requirements. This data is key to the appropriate sizing of a CHP facility. The lacking thermal data was most likely steaming rates. Often, the respondent knew the size of the facility's chillers. The price of fuel to the facility was the next on the list of things that were often not available for this screening

The ranking also shows that VA hospitals (and probably federal hospitals in general) are likely to be good CHP candidates. Large United States Postal Service facilities are next though their thermal load is more likely to be the production of chilled water. Although screening data was only provided for 2 hospitals and 3 postal centers, it is safe to say that all hospitals and postal centers are worthy of further consideration.

Gaps Regarding Entire Categories Of Federal Sites -- Data was missing for large classes of facilities. These classes included most of the VA hospitals, almost all of the other military hospitals, the large facilities of the US Postal Service, air force bases and coast guard facilities. Also missing was a thorough understanding of regional electric rates and gas rates. Often individuals contacted at the facilities were not conversant with their energy situation. The forecast that will be presented later is very rough due to this lack of information.

Enough information was made available regarding the following sites to make them worthy of further study. It is expected upon further study that these sites will prove to be economic opportunities for CHP: (listed by facility ID \#)

$\begin{array}{ll}\text { - } & 017 \\ \text { - } & 027 \\ \text { - } & 008 \\ \text { - } & 019 \\ \text { - } & 014 \\ \text { - } & 032 \\ \text { - } & 031\end{array}$

Recommendations on General Approach

The cold call nature of the initial contact with the energy personnel could have benefited from a package that would describe how the FEMP process works and a description of CHP. Most of the sites would have benefited from a technical prospectus. It is possible that ORNL send an E-Mail to all sites for which we have addresses (Thanks for cooperation, what's next and some encouragement if the site is ranked high). A two to three page description of CHP for the high ranked sites might also be an option at this time. 


\section{QUALIFIED FORECAST}

Subject to the aforementioned missing customers, Table 3 summarizes the likely prospects and rough order for the magnitude of CHP, based upon the data collected:

Table 3

\begin{tabular}{|l|c|}
\hline Source & Capacity \\
\hline Screening Responses & $268 \mathrm{mw}$ \\
\hline $\begin{array}{l}\text { Extrapolated Data Regarding USPS in } \\
\text { California }\end{array}$ & $20 \mathrm{mw}$ \\
\hline $\begin{array}{l}\text { Extrapolated Data Regarding VA hospitals in } \\
\text { California }\end{array}$ & $35 \mathrm{mw}$ \\
\hline $\begin{array}{l}\text { Extrapolated Data Regarding federal } \\
\text { hospitals in the North East }\end{array}$ & $50 \mathrm{mw}$ \\
\hline Total & $\mathbf{3 7 3} \mathbf{~ m w}$ \\
\hline
\end{tabular}




\section{Current Energy Costs Present Near Term CHP Opportunities}

Electric rates have risen dramatically for federal facilities served by either Southern California Edison's or PG\&E since June 1. Figure 1 graphically illustrates the increases of the average rates paid in both utilities:

\section{Figure 1}

\section{Impact of June 1st Increases}

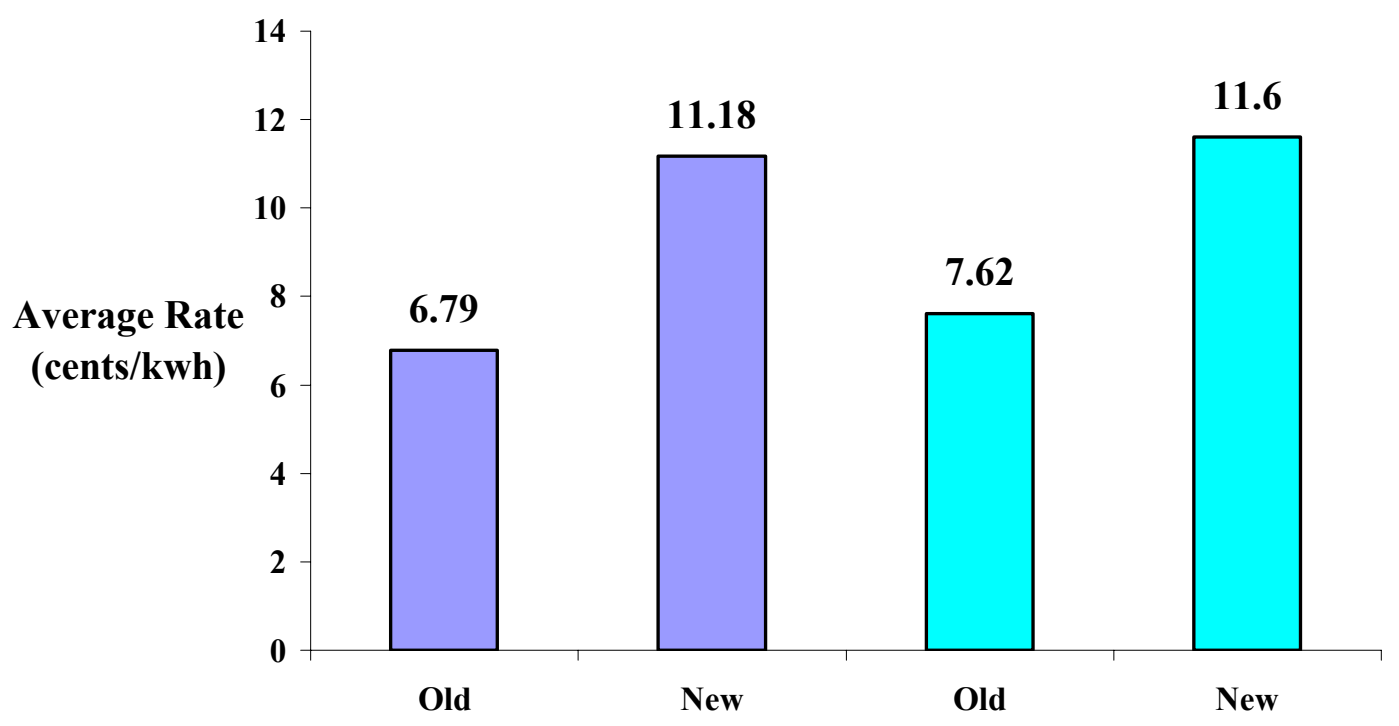

\section{Southern California Edison Pacific Gas and Electric}

The impact of these increases was amplified in that all the increases came in the volumetric portions of the rates (as opposed to increases in the fixed or demand components that may not be avoidable by onsite generation). Figure 2 illustrates the impact of this on Southern California Edison rates: 


\section{Figure 2}

Old Rates

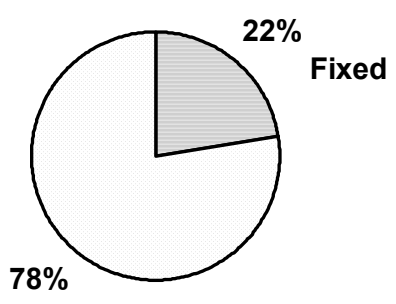

Avoidable

\section{New Rates}

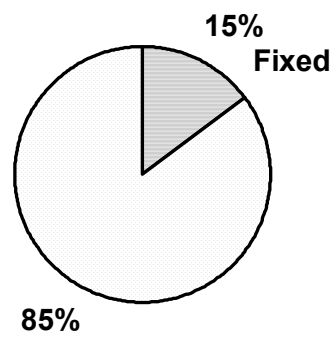

Avoidable

Figure 3

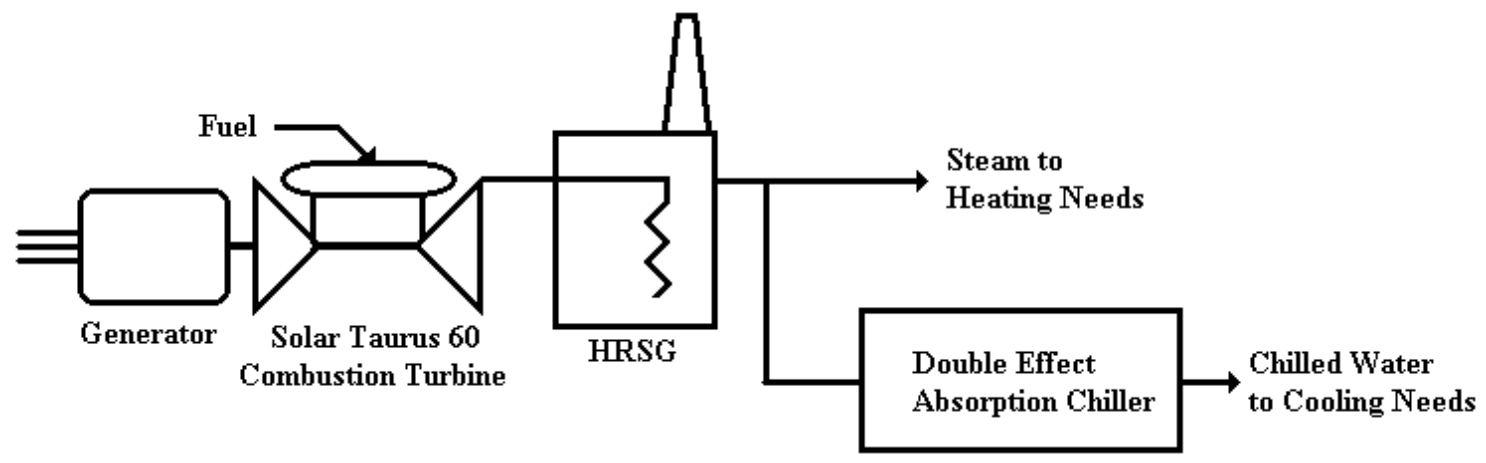

Figure 3 schematically represents a hypothetical combined heat and power system that was analyzed using three potential rate scenarios in Southern California Edison service territory. The hypothetical facility's technical features are presented in Table 4. 
Table 4

$\begin{array}{lr}\text { Generating Capacity } & 4,900 \mathrm{kw} \\ \text { Fuel Consumption } & 69 \mathrm{mmbtu} / \mathrm{hr} \\ \text { Steaming Capacity } & 26 \mathrm{mlbs} / \mathrm{hour} \\ \begin{array}{l}\text { Chilled Water Capacity (mutually } \\ \text { exclusive of Steaming Capacity) }\end{array} & 2,685 \text { Tons }\end{array}$

This analysis envisions the system operating in Southern California Edison's serving territory with that utility's tariff times of use. The facility is assumed to be providing chilled water in the "summer" (June through September) and steam for heating in the "winter" (October through May). Three rate scenarios are considered. They are described in Table 5.

Table 5

Scenario $1 \quad$ Current high TOU-8 rates persisting for three years beyond project commissioning, then rates moderating to reflect a stable wholesale clearing price for electricity.

Scenario 2 A TOU-8 rate structure that reflects a stable wholesale clearing price that is in effect with the commissioning of the project.

Scenario 3 A TOU-8 rate structure that reflects a very low wholesale price for electricity.

Southern California Edison's TOU-8 rate structure is a time of use rate that has both demand and energy components. The stable wholesale clearing price for electricity referred to above is assumed to be the replacement cost of power in the western region. This replacement cost is expected to be the price necessary for an investor to earn a reasonable rate of return on a new combined cycle merchant plant. Such a plant would have a heat rate of approximately $6,800 \mathrm{btu} / \mathrm{kwh}(\mathrm{hhv})$. The replacement cost would vary linearly with the cost of natural gas. Table 6 presents the economics assumptions used in this analysis. 
Table 6

$\begin{array}{llll} & \text { Scenario 1 } & \begin{array}{l}\text { Scenario 2 } \\ \$ 5 / \mathrm{mmbtu}\end{array} & \begin{array}{l}\text { Scenario 3 } \\ \$ 5 / \mathrm{mmbtu}\end{array} \\ \begin{array}{l}\text { Cost of Natural Gas: } \\ \begin{array}{l}\text { Average Avoided Electric Price } \\ \text { (first 3 years): }\end{array}\end{array} & 11.8 \text { cents } / \mathrm{kWH} & 7.5 \text { cents } / \mathrm{kWh} & 4.7 \text { cents } / \mathrm{kWH} \\ \begin{array}{l}\text { Average Avoided Electric Price } \\ \text { (beyond 3 }\end{array} & 7.5 \text { cents } / \mathrm{kWH} & 7.5 \text { cents } / \mathrm{kWh} & 4.7 \text { cents } / \mathrm{kWH} \\ & & & \end{array}$

Since the project is smaller the 4,900 kw, standby charges are not included in the analysis reflecting the new California state law exempting combined heat and power projects below 5 mw. Table 7 presents the simple payback of each of the aforementioned scenarios.

Table 7. Simple Payback

$\begin{array}{lr}\text { Scenario 1 } & 1.8 \text { Years } \\ \text { Scenario 2 } & 5.2 \text { Years } \\ \text { Scenario 3 } & \text { No Payback }\end{array}$

Figure 4 illustrates the cash accumulation of each of the scenarios described above.

Figure 4. Project Cash Accumulation 


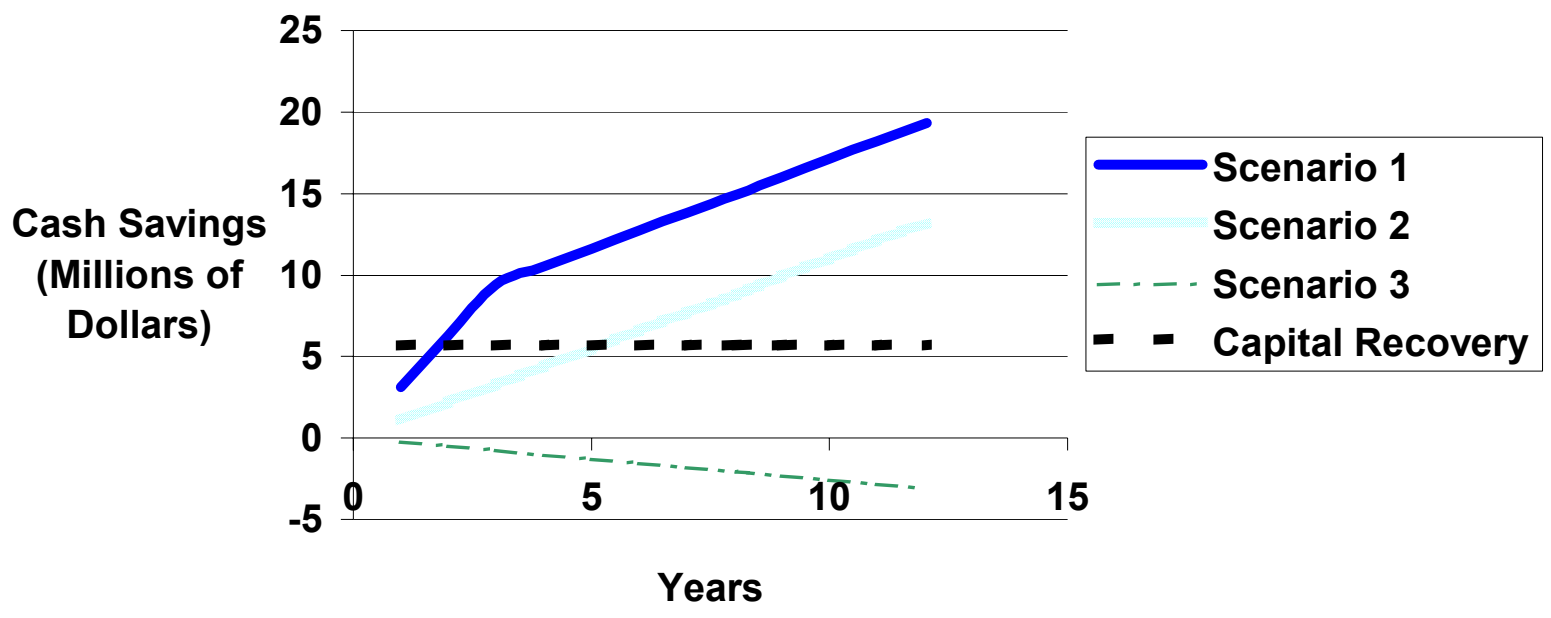




\section{Discussion}

Ultimately, combined heat and power projects will need to economically compete with the cost of generation of very efficient combined cycle plants that will represent the replacement cost of power spoken of above. At $6800 \mathrm{btu} / \mathrm{kwh}$, such a combined cycle power plant has a thermal efficiency of $50 \%$. The combined heat and power facility described above would have an overall thermal efficiency of $63 \%$. In addition to the efficiency advantage, the combined heat and power plant produces its power at or near the load thereby avoiding transmission and distribution line losses. If these losses are taken to be $8 \%$, then the efficiency with which the power is delivered to the customer by the combined cycle plant is reduced to $46 \%$.

Though the superior efficiency of combined heat and power is the major contributor to the economics described above, today and for the foreseeable future, electric rate anomalies in California present the federal government with windows of opportunities to avoid highenergy costs. Facilities installed within the next few years can expect to re- capture their capital costs within two years of commissioning under recent SCE or PG\&E tariffs. Even if then, the anomalous conditions moderate, significant energy savings will continue to reward the project developer for many years into the future. Only in the instance that a federal facility is able to buy power well below market will combined heat and power not provide an economically attractive option.

\section{CONCLUSIONS AND RECOMMENDATIONS}

\section{Conclusion}

Ongoing advances in generation technology and the restructuring of the power industry now have the potential to dramatically change the economics of CHP and on-site power generation. How and when these markets develop will depend on the extent of technology advances, the pace and ultimate direction of industry restructuring, the DG market address of environmental issues, and increased customer acceptance of the concept of on-site generation. The drivers to acceptance of distributed or on-site generation include:

Thermal energy and/or electricity cost savings Increased reliability of electric supply

Enhanced electric power quality

Security and/or independence from the local utility

This screening effort confirmed some things about CHP opportunities that many already believed to be true. There are significant CHP project possibilities within facilities owned and operated by the Federal Government. California has emerged as the preeminent area considered in this study to pursue such projects. The local utilities and governmental 
structuring or electricity and gas rates in California makes CHP viable and allows for quick recovery of first cost installations.

The current federal administration has challenged the private sector to aggressively pursue combined heat and power. Given the remarkable opportunities that exist at many federal facilities and particularly with the high electric rates and attendant economies offered in the state of California, federal agencies should take advantage of the opportunities that exist in today's market to become more efficient and environmentally sensitive. What better way for the federal government to encourage the private sector to engage in CHP projects than by leading the way?

Barriers to the CHP market in the U.S. remain. The major barriers are summarized below along with the appropriate "Pro-CHP" response:

\section{$\underline{\text { Barriers }}$}

First cost of the equipment and installation

Environmental permitting and local siting restrictions

Lack of familiarity of on-site generation

Concern about O\&M requirements and cost

Uncertainty of long term cost savings from electric restructuring

Perceived conflict with operation of core business

\section{Pro-CHP Response}

1) User-friendly life cycle cost analysis tools.

2) Awareness of third party financing alternatives.

3) Feasibility analysis demonstrating lower life cycle cost compared to not doing the project.

1) Shift to integrated environmental and energy policies.

2) Development of cost effective ultra-low emission technologies.

3) Cost effective emission controls are currently meeting even the toughest of emission standards.

Training workshops to educate facility managers and decision makers.

Economic feasibility studies should incorporate the recurring cost of annual maintenance contracts with sinking funds for major equipment overhauls

Restructuring ultimately leads to free markets in which the market clearing price will often be linked to the total operating cost of a new combined cycle. See Table 7 for the positive consequences of CHP over this alternative.

Ally with an energy service company to finance, install, and operate the CHP system. 
Onerous non-by passable charges by the local utility
Need fair standby charges and backup rates. Need to move toward regulations that incentives utilities to integrate CHP into system planning.

How successful any individual technology or product will be in the federal sector will depend on its ability to economically and reliably produce power, its ability to be widely sited without unnecessary delays and/or additional costs, and its ability to be efficiently integrated and serviced.

The following recommendations are offered:

Outreach - Develop a CHP self-evaluation guide for Federal Facility Managers, Federal Agencies, and allied ESCO's. Conduct a series of workshops on CHP technology, application, economics, operation, and maintenance. CHP is an efficiency measure that is often overlooked because of its complexity relative to other energy efficiency opportunities (such as lighting and controls). FEMP should help federal facilities to get over the initial hurdle of feasibility studies through assistance with this process.

Federal Advocacy - FEMP should assist GSA and other Federal Agencies, stay abreast of the above policy and regulatory issues affecting the viability of CHP, and should encourage active participations in the shaping of federal, state, and local regulations and legislation affecting federal facilities.

Approach the Large Ranked Facilities and their ESCOs - This is the very first, high value, early return effort that should be made. Site-specific feasibility studies ought to be performed (at least co-funded by FEMP to overcome the aforementioned inertia) in partnership with each facility and its ESCO. Some of these studies will lead to project development. Some of these large customers will have the opportunity to build CHP plants and to lead the private sector by example. This effort will also serve to teach the ESCO who may be involved with other facilities with CHP opportunities.

Obtain Region Specific Energy Cost Data - As better physical data is obtained, better regional energy cost data must be also obtained to "normalize" the opportunities and further identify the very best CHP opportunities. This data needs to be in the form of electric rate structures, anticipated electric energy costs and ought to indicate the opportunity for federal facilities to transport their own low cost gas supplies. It ought to definitively indicate which regions of the country will have the most likelihood of hosting successful CHP. It must be re-emphasized that this data will not be useful unless it includes specific data regarding the electric utilities standby charges, demand charges and exit fees.

Approach the Army and the Navy Regarding their Hospitals - Once a list of hospitals is established, the various authority structures ought to be approached for their cooperation. Specific sites ought to be discussed and agreed to for further study and implementation. Sites ought to be chosen both for their physical situation as well as the energy cost structure that exists where they are located. 
Approach the Veterans Administration - The VA is similarly situated with the military regarding their hospitals. There is a wrinkle however. Onsite Energy's screening revealed a difference of opinion regarding the VA hospitals' mission security. Some respondents believed that the country was running out of military veterans. Before anything is built, care should be taken to assure that even if the VA mission is substantially diminished, that there are plans for continued use the facilities and of course, the CHP plant.

Approach the US Postal Service - It is entirely possible that a cogeneration design for USPS facilities can be done in a "cookie cutter way" thus providing significant first cost savings. The design will probably incorporate a reciprocating engine because of this technology's fairly good efficiency even in the smaller sizes. FEMP could work with USPS to identify which regional centers ought to be first in the queue for such a "mass produced" CHP plant. Perhaps at it emerges, more modern technologies such as micro turbines and fuel cells can be considered for these applications.

Continue Screening - Federal Facilities in the US for CHP potential and expand the scope to other regions of the country. 


\section{Appendix A - CHP Background}

There are two changes that are the basis of optimism for the future of CHP. First, there have been technological improvements to increase efficiencies and reduce environmental impacts from existing CHP technologies. There has also been an expansion in the sizes and types of technologies available. These technologies are covered in detail in Technology Characterization, Section 1 of this Market Assessment Report.

The second major change affecting CHP is electric industry restructuring. It has fundamentally altered the incentives for investing in generation. No longer are vertically integrated utilities guaranteed a reasonable rate of return on all prudent investments. Utilities are being required to un-bundle generation and affiliated services from their service package. Customers have a choice of suppliers, or they can supply themselves. Some customers are aggregating for improved service offerings at lower prices. There are new opportunities and new risks for customers and energy services companies in this changing picture.

The energy cascade offered by CHP has with it attendant efficiencies in that energy normally rejected by the production of power or a process is made available for another useful purpose. CHP has emerged as a primary means of conserving fossil fuel and also mitigating the production of $\mathrm{CO}_{2}$. Electric energy was first co generated in the early $1900 \mathrm{~s}$. However with the economy of scale, cheap energy and the proliferation of the electric grid, it became difficult for these onsite-generating facilities to compete. This all changed in the late seventies when the Congress passed the Public Utilities Regulatory Policies Act (PURPA). PURPA found a way to provide incentives to use cogeneration. Many plants were built by the private sector, primarily in Texas and California.

The utilities were able to respond "competitively" through the use of exit fees, demand charges, deferral rates, and standby charges. Fixed charges went up and the price of energy went down making it more difficult to install CHP. As a result, there was a lack of new projects from the middle of the eighties until today. Many of the facilities that were built in the early eighties however, have continued to reward their owners with significantly lower overall energy costs.

Today, large merchant class power plants are difficult to build. Transmission and distribution facilities to deliver the power to the end user are becoming even more difficult to site. These difficulties ultimately translate into higher costs to the energy consumer and tightening reserves. This along with the fact that the "gas bubble" has become only a memory and the price of primary energy supplies has gone up, it becomes useful to once again to consider the cost saving efficiencies offered by CHP. 
The electric power industry is currently in an unparalleled transition period. The industry is changing from vertically integrated regulated public utility companies with franchised territories to multi-tiered competitive enterprises with regional scope. Individual states are implementing restructuring in different ways and on different time lines. Driving the changes is growing market pressures to increase customer choice and a fundamental shift in the economics of power generation and delivery. It is possible that these sweeping changes will directly affect federal facilities in their energy use and rate structures, although it is difficult to say at this time exactly how this will take shape.

In many ways the electricity market and technology changes have enabled distributed generation (DG), the placement of small power generating units (typically below $20 \mathrm{MW}$ ) at or near customer loads, to become a viable option to central station power. DG has captured the interest of policymakers at the federal and state level, excited potential users and developers, and is entering into the business strategies of many utilities and other energy service providers.

According to the DOE Energy Information Administration (EIA) base case energy forecast, approximately 393 gigawatts (GW) of new generating capacity will be needed by 2020 to meet growing demand and to replace retiring units. According to the EIA forecast, about 41 $\mathrm{GW}$ of distributed generation capacity will be added over the next 20 years. This DG component is assumed to made up of $13 \mathrm{GW}$ added directly by the electric power industry for grid support, $4 \mathrm{GW}$ of added buildings sector combined heat and power (CHP), and 24 GW of added industrial sector CHP.

While there is growing interest in and expectations for the emergence of a robust DG market, there has been limited demonstrated success in the market penetration of the federal sector facilities. There is potential for distributed generation power systems of several units per year that have not been met primarily due to competitive practices from utility tariff structuring and lack of knowledge of CHP potential. However, the market for continuousrated power generation systems in today's economy stands to gain incremental footholds due to energy market uncertainty and the need for conservation and stewardship of national fuel resources.

Following the Public Utility Regulatory Policy Act (PURPA) in 1978, there were efforts to market packaged cogeneration systems based on natural gas engines. These systems met with limited success because of high capital and maintenance costs and a hostile electric utility environment. The technology, cost and performance limitations of these systems limited market applicability to very high cost electricity areas and a narrow range of commercial and industrial end-users that could fully utilize the available waste heat.

\section{The Technical Promise of CHP}

Power generation systems create large amounts of heat in the process of converting fuel into electricity. For the average power plant, over two thirds of the energy content of the input fuel is converted to heat and wasted. As an alternative, an end-user with significant thermal 
and power needs can generate both its thermal and electrical energy in a single combined heat and power system located at or near its facility. CHP, also called cogeneration, can significantly increase the efficiency of energy utilization, reduce emissions of criteria pollutants and $\mathrm{CO} 2$, and lower operating costs for industrial, commercial and institutional users. CHP has been used by some industries such as pulp and paper and petroleum for over 100 years to meet their steam and power needs.

\section{$\underline{\text { CHP Development Under PURPA }}$}

The Public Utilities Regulatory Policy Act (PURPA) of 1978 was enacted during the Carter Administration as a reaction against the "energy crisis" and the perception of a short supply of natural gas. Its purpose was to increase supply-side energy conservation (efficiency) and to diversify fuel resources. The cogeneration rules in PURPA were designed to increase efficiency of fuel use by removing regulatory and institutional barriers to the development of CHP. PURPA stimulated the market, primarily for large CHP systems, by requiring utilities to interconnect with qualified CHP facilities, provide backup power at reasonable rates, and purchase any excess electricity at the same rate the utilities would have had to pay to generate it themselves. PURPA successfully removed barriers to CHP. Total U.S. capacity increased from about $10,000 \mathrm{MW}$ in 1980 to over 44,000 MW in 1995-but it also encouraged capacity sales in some regions of the country that exceeded incremental requirements. Lucrative power contracts spurred development of so-called "PURPA machines" during this period that often maximized electric output at the expense of overall efficiency.

To qualify for PURPA benefits small power producers and cogenerators had to file with the Federal Energy Regulatory Commission (FERC) as "Qualifying Facilities" or QFs. The QFs had to meet minimum useful thermal energy and overall efficiency requirements. Utilities were required to purchase power from QFs at a rate not to exceed their own avoided cost. Purchasing power at avoided cost was designed to give assurance that the public would not pay more for power from QFs than it did from the utilities.

California's investor-owned utilities issued Interim Standard Offer Contracts to QFs for power purchases. The Interim Standard Offer contracts for long-term energy and capacity are known as Interim Standard Offer 4 (ISO4). ISO4 contracts provide the option for some QFs to obtain fixed energy prices for up to 10 years, after which energy prices revert to the short-run avoided cost of the purchasing utility. PURPA and ISO4 contracts fostered a dynamic cogeneration industry in California from the mid-1980s to the early 1990s. Over 6400 MW of cogeneration was subscribed in California between 1982 and 1993.

\section{The Market Levels Off}

Lower avoided costs and increasing utility resistance led to a decline in the CHP market in the mid 1990s. Since PURPA was enacted, avoided costs have dropped from between $\$ 0.04$ and $\$ 0.07 / \mathrm{kWh}$ to approximately $\$ 0.025 / \mathrm{kWh}$, due to low natural gas prices and improved technologies. 
Southern California Edison and San Diego Gas and Electric petitioned the FERC to void a 1993 California PURPA auction. The companies claimed that the CPUC had forced them to accept several hundred megawatts of renewable energy (geothermal wind) priced at above 6 cents per $\mathrm{kWh}$ compared to available new gas-fired capacity 4 cents per $\mathrm{kWH}$. In a landmark decision, the FERC agreed with the utilities that, given the emerging competitive landscape, avoided-cost determinations had to be open to all sellers to accurately measure the avoided cost. The FERC's decision had a chilling effect on the CHP market and new PURPA auctions were put on hold.

\section{Opportunities for CHP in a Restructured Electricity Market}

The new electricity market opened in California on March 31, 1998 giving all electricity customers in the state a choice of energy service providers. This retail market for electricity was created by the passage of California electricity-restructuring legislation contained in Assembly Bill 1890. Under AB1890, Pacific Gas \& Electric (PG\&E), Southern California Edison (SCE) and San Diego Gas \& Electric (SDG\&E), also called Utility Distribution Companies (UDCs), are required to make all their power purchases from the state-created market for power called the Power Exchange (PX). Any generators of electricity are allowed to bid their power into this wholesale PX auction market. An Independent System Operator (ISO) was also set up to manage the California transmission system and to ensure the availability of power.

As part of restructuring, the utilities have been encouraged to divest themselves of generation in order to reduce the opportunity to exercise market power in the energy market. More of the central station generation is moving into private hands, and there is indication that the new owners will re-power or otherwise modify them to operate more efficiently. There are many opportunities to sell the energy from these plants as wholesale bulk power through the California Department of Water Resources or other exchange, or to serve the ancillary services market of the ISO, as well as traditional bilateral short or long-term contracts with UDCs. Owners will operate the plants to maximize profits on energy sales, not to obtain a fair rate of return under a managed regulatory regime.

Under restructuring, CHP must compete on a cents per kilowatt-hour basis with central station power if it presumes to play in the same energy markets. For the reasons stated above, (and the initial experiences of California not withstanding) competition should ultimately drive electricity prices lower into the future than they would have been under traditional regulation. CHP has the opportunity to flourish only if the economics work in this competitive market.

Reduction of retail electricity prices brought about by restructuring decreases the value of power generated on-site, and lengthens the payback on CHP. At the same time, under restructuring, small-to-medium-sized industrial facilities and commercial/institutional facilities may see their peak electricity rates increase, increasing the value of on-peak use of CHP. Customers who are considering installing CHP will need to match their internal electric and heat loads with the value of energy to maximize the return on CHP. 


\section{Potential Benefits of CHP}

\section{Efficiency}

Figure A-1 shows how a well-balanced CHP system outperforms a traditional remote electricity supply and boiler combination. The chart illustrates that out of 100 units of input fuel, CHP converts 89 to useful work: 39 to electricity and 50 to useful steam. Traditionally separated heat and power components require 189 units of energy to accomplish the same end use tasks.

Figure A-1

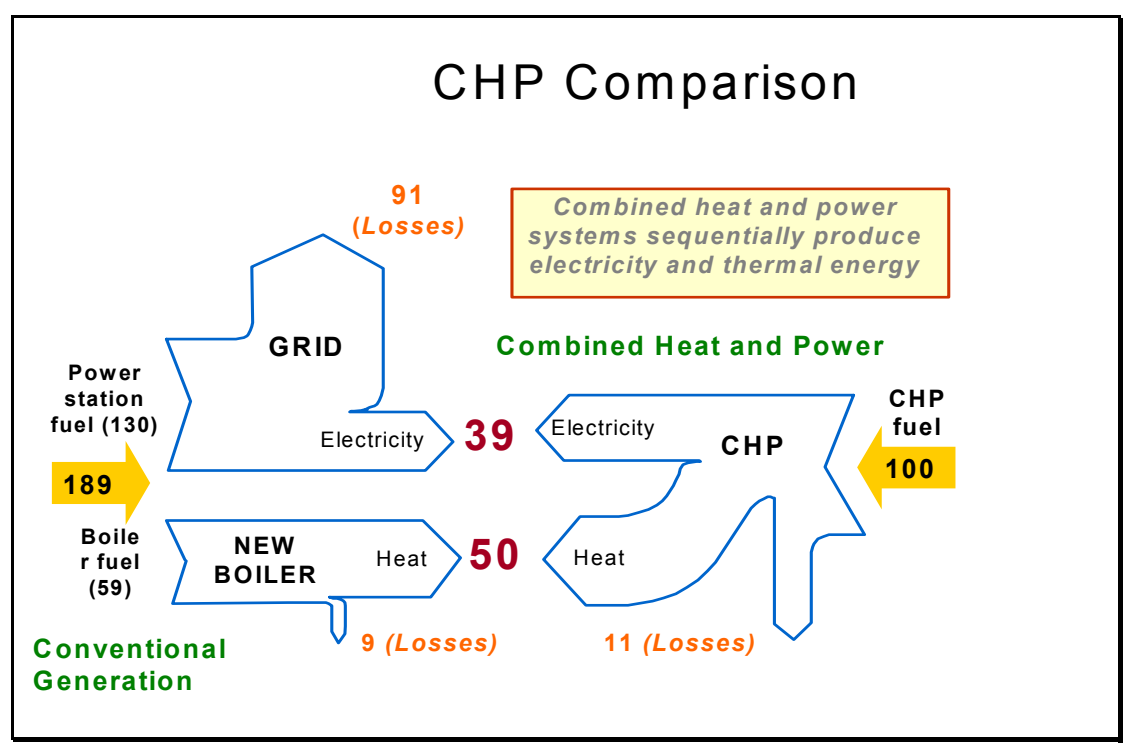

Figure A-1 above shows how out of 100 units of input fuel, CHP converts 89 to useful work, 39 to electricity and 50 to heat to a boiler. Traditional separated heat and power components require 189 units of energy to accomplish the same end use tasks.

\section{Emissions Reductions}

By increasing the efficiency of energy use, CHP can significantly reduce emissions of criteria pollutants such as $\mathrm{NO}_{\mathrm{x}}$ and $\mathrm{SO}_{2}$, and non-criteria greenhouse gases, such as $\mathrm{CO}_{2}$. Figures A-2 and A-3 show $\mathrm{NO}_{\mathrm{x}}$ and $\mathrm{CO}_{2}$ emissions comparisons respectively by power generation technology and fuel type. 
Figure A-2

\section{$\mathrm{NO}_{\mathrm{x}}$ Implications of CHP}

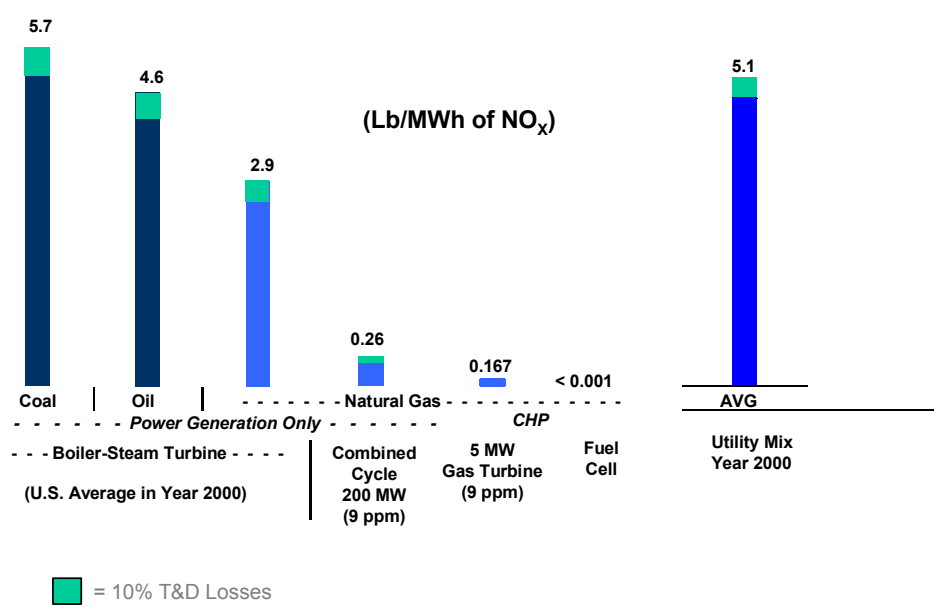

Figure A-3

\section{Global Warming Implications of CHP}

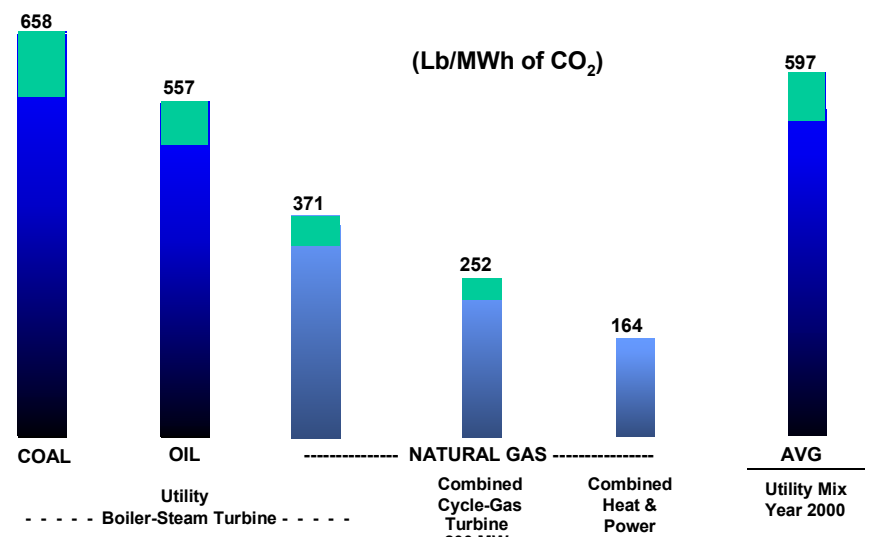

$=10 \% \mathrm{~T} \& \mathrm{D}$ Losses

Source: GRI Report Light Duty Vehicle Full Fuel Cycle Emissions Analysis, 1994

Gas Turbine Environmental Analysis and Policy Considerations, Onsite Energy, 1997 


\section{$\underline{\text { CHP Economics }}$}

The economics of CHP can be compelling when compared to large customer electric rates. Figure A-4 indicates the price points for several CHP technologies as compared to the U.S. large customer electricity price distribution. The figure shows that a $5 \mathrm{MW}$ CHP system is competitive with delivered electricity prices for 37 percent of large customers. For a $30 \mathrm{MW}$ system the comparison shows that CHP exhibits economic potential for 68 percent of large customers. A $1 \mathrm{MW}$ reciprocating engine system is competitive in 20 percent of the large customer class. The comparison is based on \$3.50/MMBtu natural gas cost for the CHP system and the avoided boiler fuel.

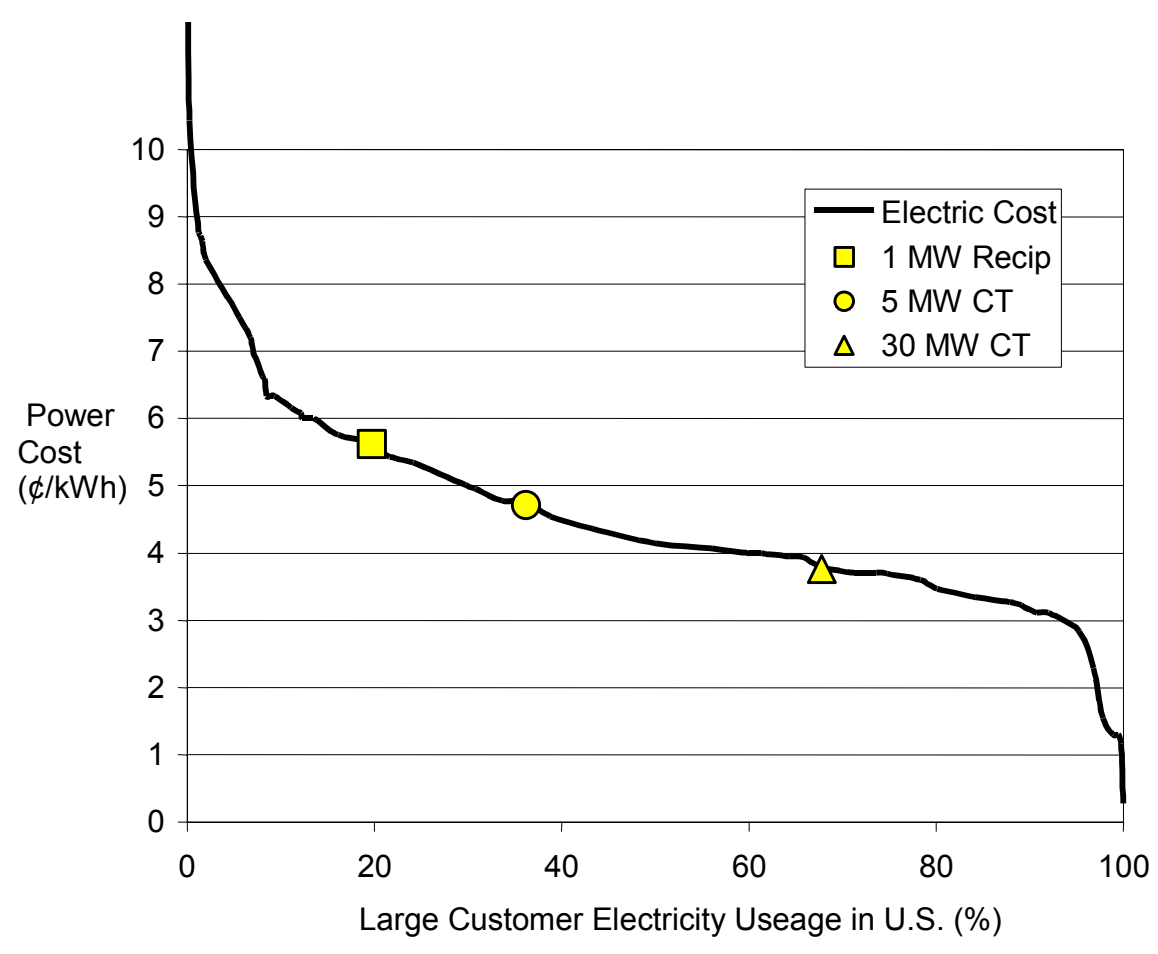

Figure A-4. Comparison of CHP Net Power Costs to U.S. Large Customer Electricity Prices

\section{Ancillary Benefits}

In a restructured electric industry, CHP and other distributed generation options can offer grid support to the distribution utility. They also give energy service providers (ESP's) the ability to offer ancillary benefit services, including: 
* Voltage and frequency support to enhance reliability and power quality;

* Avoidance or deferral of high cost, long lead time T\&D upgrades;

* Bulk power risk management

* Reduced line losses

* Reactive power control

* Reduced central station generating reserve requirements;

* Transmission capacity release

Energy services providers are working now to determine the quantity and value of benefits derived from grid support and ancillary services that accrue from installing CHP and other DG systems.

\section{MARKET BARRIERS}

Historically, CHP and other forms of on-site generation have faced severe market and regulatory barriers. These include utility practices and electricity rate designs that discourage on-site generation, lengthy and costly environmental permitting and siting processes, uneven tax treatment of on-site generation assets and high customer hurdle rates for energy related investments.

\section{Grid Interconnection}

Grid interconnection requirements that are non-standard, out-dated and overly stringent have been a barrier to widespread deployment of distributed generation technologies. Interconnect requirements vary by state and/or utility and are often not based on state-of-theart technology or data. Compliance often requires custom engineering and lengthy negotiations that add cost and time to system installation. These requirements can be especially burdensome to smaller systems (under $500 \mathrm{~kW}$ ). Non-standard requirements also make it difficult for equipment manufacturers to design and produce modular packages. Lack of interstate or intrastate uniformity discourages the economic business case for CHP in all markets and applications.

Utilities have many legitimate interconnection concerns. First, safety of line personnel must be maintained at all times. This means the CHP system must provide assurance that in the event the utility takes a line out of service for maintenance or any other reason, the CHP system will not inadvertently energize this circuit. Second, safety of equipment must not be compromised in any way. A CHP system failure must not cause damage to other customer sites or to the system to which it is connected. Reciprocally, a utility distribution system fault must not have the ability to damage the CHP system. Third, the reliability of the CHP system must not be compromised in any way.

Public utility commissions in California, Texas and New York are focusing on interconnection issues and are moving toward the development of more equitable standards. The results from these efforts will help define the issues more clearly. Industry standards organizations, especially Institute of Electrical and Electronic Engineers (IEEE), will 
provide a forum for ratifying and issuing national interconnection standards. The Electric Power Research Institute (EPRI) is beginning to evaluate the effect of increased deployment of on-site generation on grid system dynamics and is exploring the development of controls and communications protocols to facilitate grid dispatch and interface.

\section{Potential Stranded Assets and Exit Fees}

Electric utilities have argued that a customer's installation of onsite generation may strand physical assets already existing that were placed into service for that particular customer's use. The utilities' position is that stranded assets can consist of portions of the distribution system, transmission system or even generating capacity. When a customer withdraws his load from the system, the cost of these stranded assets can place a financial burden on the utility or its other customers. This argument then forms the basis of the utilities' contention that they are allowed to collect exit fees from those customers withdrawing their load from the system. Exit fees can consist of a one-time charge or even a surcharge charged against every $\mathrm{kWh}$ that the onsite generates.

\section{Standby/Back-up Charges}

On-site CHP usually requires back-up power for generation outages or to cover routine system maintenance. Currently utilities charge for power used and for reserved generation and distribution capacity. Unreasonably high charges for these services have been barriers to on-site generation. In a restructured market, the generation back-up charge will be negotiated between the user and generation supplier. Regulators will continue to set the distribution rates, attempting to balance utility and user needs and to protect the interest of ratepayers. The burden of the standby charges can be high. The CHP site will receive a bill either for rated capacity or customer's peak demand; whichever is lower.

\section{Environmental Barriers}

The most notable environmental barrier for CHP is the air quality permitting process and regulatory requirements. The air quality permitting process for various CHP technologies can be complex, lengthy, and costly. In particular, fossil fuel fired units such as turbines and IC engines are typically required to meet stringent NOx emission standards. This results in potentially burdening the CHP economics. The complexity of permitting results from regulatory requirements that differ among the various air districts. The lengthy permitting process results from the evaluation of New Source Review (NSR) requirements such as best available control technology (BACT) and lowest achievable emission rate (LAER), as well as addressing emission increases that must be offset by emission reduction credits (ERCs). The costly component of air quality permitting not only results from the lengthy permitting process but the potential need to install more costly controls and/or the need to purchase ERCs to offset emissions.

The air quality regulatory requirements differ from district to district because not all districts have the same rules to implement their attainment strategy plans. Districts that are greatly exceed the ozone standards have more stringent permitting requirements, as well as source specific requirements, compared to the requirements of districts that meet the ozone standards. Therefore, approaching the permit process requires complying with local standards and regulations and typically requires a customized approach for each district. 
Some districts may require more information than others, processing fees may be more expensive and air toxics impacts may be of concern in certain areas. Furthermore, regulations continue to change as technology improves and as the district approaches attainment, or conversely as the districts air quality worsen.

The permitting process can be lengthy and costly particularly for CHP projects that qualify as major sources requiring NSR permitting. When an emission standard and/or control technology is demonstrated in the field, districts tend to adopt the most recent and lowest standard as the benchmark for meeting emission standards. For example, with respect to gas turbines, regardless of the size (e.g., MW), the same type of controls and emission standards are imposed on the smaller units as are imposed on much larger turbines, even though there may be a relatively high cost for control installations. Demonstrating that a type of control technology is not feasible or not cost-effective can result in many iterations and negotiations with the local air district, as well as oversight state and federal agencies. With respect to emission standards, typically concentration rates (ppm) are set at emission standards, and these generally do not reflect the resulting efficiencies associated with thermal output; that is, standards are not set for CHP type sources that are in lb/MW-hr values. Additionally, depending on the project configuration, location and aggregate emissions of a CHP project, emission offsets may be required. This can be costly if the local supply of offsets is low; sellers may increase their sale price.

\section{Financial Barriers}

Depreciation schedules for CHP equipment are not consistent. Industrial depreciation schedules ramp down over a fifteen-year life of equipment; commercial technologies have 25-35 year depreciation period. This disparity puts CHP at a competitive disadvantage when compared to central station power.

\section{Siting Barriers}

Siting of CHP equipment involves approval by local agencies and acceptance by the affected communities. Also, the local utility distribution company must approve the grid interconnection, as previously discussed. Agencies include the local fire departments, building departments, planning departments, and air quality districts. On a policy and planning level, local community planning groups may also be involved; such groups monitor the growth issues of their community, as well as actively participate in the land use planning issues.

Most of the concerns and issues involved in the CHP siting process are legitimate land-use planning issues. The additional burden on CHP comes from a lack of knowledge by local authorities and community leaders of CHP technologies. This fact is not helped but hindered by the lack of standards for small CHP equipment. Most CHP equipment operations are fairly straightforward, but some agencies request information that can delay installing the equipment, due to unfamiliarity with the technology. The agencies sometimes require construction 'over-design', which can increase the cost of installation. 
As mentioned above, standards are not developed for small CHP units. Fire departments must ensure that there are no fire and safety hazards; with the potential installation of small units in common places such as shopping centers and other general public spaces, such units come under much more scrutiny. Likewise, building and construction inspectors' lack of familiarity with the units can result in requirements that exceed current standards and codes. Because CHP equipment may be required to install air pollution control technology, hazardous materials (e.g., ammonia, sulfuric acid) may be involved. Additional approvals are needed to ensure onsite safety, and proper handling and transport of hazardous materials, as well as ensuring that measures are taken to minimize and eliminate accidental releases of hazardous materials.

For units that may be sited in neighborhood communities, issues that arise include noise and visual/aesthetics, as well as air quality impacts for certain types of CHP units. Land use issues arise if there is a concern with zoning or proximity to sensitive receptors such as schools, hospitals, day care centers and environmentally sensitive areas. For areas that are rapidly growing, amendments must be made to zoning and/or the land use plans if a proposed site is not properly zoned; this can be timely and involve not only an agency review but community acceptance. Depending on the level of community concern and lack of knowledge of CHP technologies and benefits, CHP projects may be faced with meeting conditions beyond standards and requirements governed by agency requirements and be designed as projects prescribed by community needs. 


\section{Appendix B - Data Collection}

The data collection form used for the Screening is contained on the next page. 


\section{ORNL - FEMP Data Collection}

Date:

Name (and title) of contact:

Agency Site Name:

Address:

Central Plant Name (if appropriate):

1. What is the electrical load of your facility? Is the electrical load greater than 1 megawatt? Yes (circle one)

No

2. Steam and/or hot water and chilled water are primarily produced in (choose one):

A Central Plant:

Scattered Chillers, Hot Water Heaters and Boilers:

To what extent (Scattered) $0 \ldots \ldots . .1 \ldots \ldots . .2 \ldots \ldots . . .3 \ldots . . . .4 \ldots \ldots . .5$ (Central)

If no central plant, any plan or interest in future development of mechanical room.

3. What are you currently paying for your electricity rates?

Do you consider the rates that your facility is paying for electricity to be high?

(inexpensive) $0 \ldots \ldots . .1 \ldots \ldots . .2 \ldots \ldots . . . . \ldots \ldots . . . . \ldots . .5$ (overpriced)

4. Is your electrical supply reliable? (note: system increases score for decreased stability)

(very reliable) $0 \ldots \ldots . . .1 \ldots \ldots . . .2 \ldots \ldots . . . . . . . .4 \ldots \ldots . .5$ (very unreliable)

Electric Utility:

Electricity Commodity Provider:

Number of Electric Utility Meters:

Utility Delivery Voltage:

5. Has your facility experienced blackouts? Yes (circle one) No

How many blackouts in the last quarter? Cost to facility:

6. Is the facility power load flat or spiked with peaks and bases?

(high fluctuations) $0 \ldots . . . . .1 \ldots \ldots . . .2 \ldots . . . .3 \ldots \ldots . . . .4 \ldots . . .5$ (flat)

Is there standby genset? (Yes / No) If yes what kw:

7. Is there an unmet need for stand-by power?

Yes (circle one) No If yes what KW?

8a. Power Consumption Can Be Considered:

(Seasonal) 0.......1.......2..............4......5 (Consistent)

8b. Annual Energy Use: Peak / Base Demand is flat or spiked with peaks and valleys? $\mathrm{MWH}$

I MW 
What is your fuel source? (circle one) Nat Gas, Propane, Oil, Coal, Other

If combined fuel sources, please describe:

What is the cost per unit measure of your fuel source?

Daily fuel cost:

Monthly fuel cost:

Annual fuel cost:

Who is the Gas Commodity Supplier:

Who is the Gas Utility:

9. What is the condition of facility boilers and chillers?

(failing) $0 \ldots \ldots . . . . . \ldots . . .2 \ldots \ldots . . .3 \ldots . . .4 \ldots \ldots . .5$ (excellent condition)

Condition of Current Boilers and Chillers:

Condition of Central Distribution System:

Major Equipment in Central Plant [Chillers (indicate electric or steam fired) and boilers]:

Type:

Size:

Age:

\# of units:

Type:

Size:

Size:

Age:

\# of units:

Type:

Size:

Age:

\# of units:

Type:

Age:

\# of units:

Brief description of the central plant: [Steam (Pressure) or hot water (temp), chilled water?]

What is the Peak and Base daily demand for:

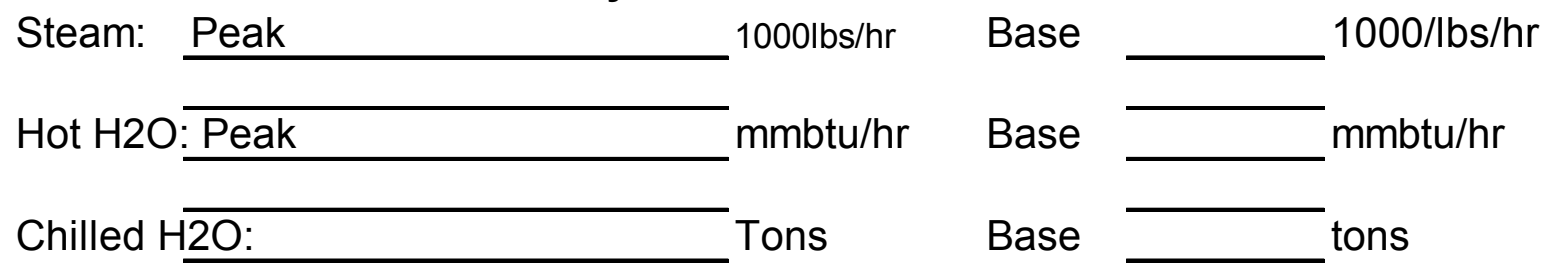

What is the annual Peak and Base demands for:

\begin{tabular}{|c|c|c|}
\hline Steam: & Peak: & $1000 \mathrm{lbs} / \mathrm{hr}$ \\
\hline & Minimum: & $1000 \mathrm{lbs} / \mathrm{hr}$ \\
\hline $\mathrm{Hot} \mathrm{H} 2 \mathrm{C}$ & Peak & $\mathrm{mmbtu} / \mathrm{hr}$ \\
\hline & Minimum: & $\mathrm{mmbtu} / \mathrm{hr}$ \\
\hline Chilled & -20: & tons \\
\hline & Base & tons \\
\hline
\end{tabular}

10. Are the Air Quality requirements strict at your facility?

(strict) $0 \ldots \ldots . . . . . \ldots . . . . . . .3 \ldots \ldots . . . . . . . .5$ (lenient)

11. Is there a licensed, stationary engineer onsite?

Yes (circle one) No

12. What is the Thermal Load of this facility?

Approx. how much square footage is served by plant?

Approx. what is the total square footage of the facility?

Percentage of total facility space served by plant? 
Existing CHP (Yes/No): If yes who on-site would have the most corporate memory of Recent CHP Studies and Plans:

Capacity: kw (comments)

Agency Site Mission Stability (i.e., growing, secure, in jeopardy):

To what extent is DSM (Demand Site Management) implemented?

(Not implemented at all) $0 \ldots . .1 \ldots .2 \ldots . . . . .4 \ldots .5$ (Completely implemented)

Have you implemented energy improvements through Area Wide Agreements:

explain:

Any ESCO Alliance(s)?:

Do you participate in any load curtailment program? (Yes / No) (circle one)

Would you be willing to collaborate with FEMP on a CHP feasability study?

\begin{tabular}{ll}
\hline Agency Site Contact(s): & Name: \\
Name: & Title: \\
Title: & Phone: \\
Phone: & Fax: \\
Fax: & E-mail: \\
E-mail: & \# years \\
\# years &
\end{tabular}




\title{
Appendix C - Excerpt Federal CHP Resource Guide
}

\author{
(An adaptation from Combined Heat and Power: A Federal Manager's Resource \\ Guide, available at http://www.eren.doe.gov/femp/resources/pdfs/chp.pdf)
}

Undertaking a CHP project should be viewed as a long-term investment, in terms of planning, implementation, and operation. The feasibility of applying combined heat and power (CHP) technologies within federal government facilities is dependent upon identifying the best uses of CHP and assuming an appropriate investment time frame. The proper planning of all key aspects of a medium- to large-scale successful CHP project including financial, regulatory, legal, environmental, engineering, and other issues requires that the facility's mission duration match the time required to achieve the expected benefits from full CHP implementation. Many federal facilities that expect to downsize in the future may need to more carefully consider the CHP potential and economics at their facility.

Larger Federal building sites, including military bases, multi-building medical centers, national laboratory complexes, and training/research centers, have the largest purchased fuel and electric power requirements. Therefore, these larger Federal facilities will reap the greatest financial benefit from applying existing CHP technology. It is important to note that the financial benefits from a CHP project will depend upon the amount of the purchased thermal and electric power that the CHP system is replacing.

\section{$\underline{\text { Near Term CHP Projects }}$}

- Department of Veterans Affairs and DOD medical centers (because these multibuilding centers have a fairly flat thermal load due to constant need for heating domestic hot water, heating service water for reheat coils, and sterilizing medical equipment)

- Federal correctional facilities in heating dominated climates (because these buildings have a need for the thermal output from a CHP system for both space heating and domestic hot water heating)

- Federal office building complexes (such as multiple-building Federal facilities that could use the thermal output from a centralized CHP system as the input to absorption cooling equipment to achieve higher overall efficiency)

- Government Owned/Contractor Operated (GOCO) manufacturing and research facilities (because many manufacturing and research processes require steam or other thermal power for the production of industrial or research products) 


\section{A Few Years From Now}

- Larger (500,000 sq. ft. and larger) stand-alone Federal buildings located in areas not served by district steam or district chilled water systems. These larger Federal office buildings can use the thermal output from a CHP system to provide the needed heatsource for absorption cooling equipment.

- Military base-wide steam heating systems that have large central plant boilers or central loops during the summer or other off-peak periods

\section{Long-term Prospects ( 5 or more years)}

- Medium-sized Federal buildings that can use the thermal output as the source for operating absorption cooling equipment in summer.

- Military base light industrial facilities (such as welding, vehicle engine repair shops, machine shops) that need peak power use and can use the thermal output for process steam. Five years from now, CHP technologies will likely be less expensive to install and will have greater output per unit of input fuel. In-creases in the cost of fuel oils and natural gas can result from inter-national events beyond the control of fuel suppliers, but this will result in a greater life cycle cost savings for all CHP technologies. Thus, as the range of applications for CHP grows the economics of CHP will become more attractive. 


\section{Appendix D - Site Log}

\begin{tabular}{|c|c|c|c|c|c|c|c|c|c|c|c|}
\hline \multirow[t]{2}{*}{$\begin{array}{c}\text { California } \\
\text { Size Site } \\
\text { Class } \\
\end{array}$} & $\begin{array}{c}\text { \# of sites } \\
\text { in Femp } \\
\text { Tracks }\end{array}$ & \multicolumn{5}{|c|}{$\#$ of sites not contacted } & \multicolumn{4}{|c|}{ Sites contacted } & \multirow[b]{2}{*}{ Total } \\
\hline & & $\begin{array}{c}\text { Base } \\
\text { Closures }\end{array}$ & $\begin{array}{l}\text { Pending } \\
\text { agency } \\
\text { response }\end{array}$ & $\begin{array}{c}\text { desk } \\
\text { screening }\end{array}$ & $\begin{array}{l}\text { couldn't } \\
\text { locate } \\
\text { contact }\end{array}$ & total & $\begin{array}{c}\text { Not } \\
\text { Interested }\end{array}$ & $\begin{array}{c}\text { No } \\
\text { Central } \\
\text { Plant }\end{array}$ & L/MW & $\begin{array}{c}\text { Central } \\
\text { Plant }\end{array}$ & \\
\hline $5000000+$ & 21 & 5 & 0 & 2 & 0 & 7 & 9 & 0 & 0 & 4 & 14 \\
\hline $\begin{array}{l}1,000,000 \text { to } \\
5,000,000\end{array}$ & 48 & 10 & 6 & 6 & 3 & 25 & 12 & 4 & 0 & 6 & 23 \\
\hline $\begin{array}{l}500,000 \text { to } \\
1,000,000\end{array}$ & 21 & 3 & 4 & 2 & 0 & g & 10 & 4 & 0 & 1 & 12 \\
\hline $\begin{array}{l}100,000 \text { to } \\
500,000\end{array}$ & 74 & 4 & 31 & 12 & 4 & 51 & 9 & 10 & 0 & 3 & 23 \\
\hline Totals & 164 & 22 & 41 & 22 & 3 & $\overline{92}$ & 40 & 14 & 0 & 14 & 72 \\
\hline
\end{tabular}

\begin{tabular}{|c|c|c|c|c|c|c|c|c|c|c|c|}
\hline $\begin{array}{l}\text { New England Size } \\
\text { Site Class }\end{array}$ & $\begin{array}{c}\text { \# of sites in Femp } \\
\text { Tracks }\end{array}$ & \multicolumn{5}{|c|}{ \# of sites not contacted } & \multicolumn{4}{|c|}{ Sites contacted } & \multirow[b]{2}{*}{ Total } \\
\hline & & $\begin{array}{c}\text { Base } \\
\text { Closures }\end{array}$ & $\begin{array}{c}\text { Agency } \\
\text { wide } \\
\text { response }\end{array}$ & $\begin{array}{c}\text { desk } \\
\text { screening }\end{array}$ & $\begin{array}{l}\text { couldn't } \\
\text { locate } \\
\text { contact }\end{array}$ & total & $\begin{array}{c}\text { Not } \\
\text { Interested }\end{array}$ & No Central & L/MW & $\begin{array}{c}\text { Central } \\
\text { Plant }\end{array}$ & \\
\hline $5,000,000+$ & 5 & 3 & $\begin{array}{r}0 \\
\end{array}$ & 0 & 0 & 3 & 1 & 0 & 0 & 1 & 5 \\
\hline $\begin{array}{l}5,000,000 \text { to } \\
1,000,001\end{array}$ & 30 & 6 & 2 & 0 & 5 & 13 & 11 & 4 & 0 & 2 & 17 \\
\hline $\begin{array}{l}1,000,000 \text { to } \\
500,001\end{array}$ & 48 & 5 & 7 & 0 & 15 & 27 & 12 & 5 & 0 & 4 & 21 \\
\hline $\begin{array}{l}500,000 \text { to } \\
100,000\end{array}$ & 114 & 9 & 35 & 0 & 35 & 79 & 25 & 9 & 0 & 1 & 35 \\
\hline Total & 197 & 23 & 44 & 0 & 55 & 119 & 49 & 18 & 0 & 6 & 78 \\
\hline
\end{tabular}

\begin{tabular}{|c|c|c|c|c|c|c|c|c|c|c|c|}
\hline $\begin{array}{c}\text { Texas Facility } \\
\text { Size Site Class }\end{array}$ & $\begin{array}{c}\text { \# of sites } \\
\text { in Femp } \\
\text { Tracks }\end{array}$ & \multicolumn{5}{|c|}{ \# of sites not contacted } & \multicolumn{4}{|c|}{ Sites contacted } & \multirow[b]{2}{*}{ Total } \\
\hline & & $\begin{array}{c}\text { Base } \\
\text { Closures }\end{array}$ & $\begin{array}{l}\text { Agency } \\
\text { wide } \\
\text { response }\end{array}$ & $\begin{array}{c}\text { desk } \\
\text { screening } \\
\end{array}$ & $\begin{array}{l}\text { couldn't } \\
\text { locate } \\
\text { contact }\end{array}$ & total & $\begin{array}{c}\text { Not } \\
\text { Interested }\end{array}$ & $\begin{array}{c}\text { No } \\
\text { Central } \\
\end{array}$ & L/MW & $\begin{array}{c}\text { Central } \\
\text { Plant } \\
\end{array}$ & \\
\hline $5000000+$ & 0 & 0 & 0 & \begin{tabular}{|l|}
0 \\
\end{tabular} & 0 & 0 & | & 0 & 0 & 0 & 0 \\
\hline $\begin{array}{l}1,000,000 \text { to } \\
5,000,000\end{array}$ & 32 & 0 & 0 & 9 & 0 & 9 & 17 & 0 & 0 & 6 & 23 \\
\hline$\frac{5,000,000}{500,000 \text { to }}$ & & & & & & & & & & 6 & 23 \\
\hline $1,000,000$ & 14 & 0 & 0 & 4 & 0 & 4 & 8 & 0 & 0 & 2 & 10 \\
\hline 100,000 to & & & & & & & & & & & \\
\hline 500,000 & 89 & 0 & 0 & 68 & 0 & 68 & 19 & 0 & 0 & 2 & 21 \\
\hline \begin{tabular}{|l|l|} 
Total \\
\end{tabular} & 135 & 0 & 0 & 81 & 0 & 81 & 46 & 0 & 0 & 10 & 54 \\
\hline
\end{tabular}




\section{Appendix E - QF CHP Plants that may serve Federal Facilities}

\begin{tabular}{|l|l|l|r|r|}
\hline FACLNAME & FACLSTREET & FACLCITY & FACLSTATE & FACLZIP \\
\hline Division & 3200 Harbor Drive & San Diego & CA & 92113 \\
\hline EI Cajon & 800 West Main Street & El Cajon & CA & 92020 \\
\hline Kearny & 5460 Overland Ave & San Diego & CA & 92123 \\
\hline Miramar & 6897 Consolidated Way & San Diego & CA & 92121 \\
\hline Naval Station & 3427 Surface Nave Blvd & San Diego & CA & 92136 \\
\hline North Island & 370 Rogers St \& Quay Road & Coronado & CA & 92135 \\
\hline NRG Norwalk Harbor Generating Station & Manresa Island Avenue & South Norwalk & CT & u/k \\
\hline Naval Training Center & 566 Neville Road & San Diego & CA & 92133 \\
\hline Charleston Resource Recovery Facility & 2550 Spruill Avenue & North Charleston & SC & 29405 \\
\hline Fort Drum H T W Cogeneration Facility & 2nd Street East Oneida Ave & Fort Drum & NY & 13603 \\
\hline Corona Cogen & 1130 West Rincon & Corona & CA & 91720 \\
\hline NTC MCRD Energy Facility & Seville Road & San Diego & 92140 \\
\hline Naval Station Energy Facility & CA & 92136 \\
\hline North Island Energy Facility & Rogers Road at Quay Street & Coronado & CA & 92139 \\
\hline Veterans Home of California & Yountville & CA & 94599 \\
\hline U S Agri Chemicals Corp Fort Meade Chemical Prod & 3225 County Road 630 West & Fort Meade & FL & 33841 \\
\hline Utility Plants Section & 1060 Gaffnay Boulevard 6500 & Fort Wainwright & AK & 99703 \\
\hline Eielson Air Force Base Central Heat & Eielson AFB & AK & 99702 \\
\hline Radford Army Ammunition Plant & 6203 Ravens Way & Radford & VA & 24141 \\
\hline Naval Submarine Base Kings Bay GA & & Kings Bay & GA & 31547 \\
\hline Fort Greely Power Plant & & AK & 99508 \\
\hline Brooklyn Navy Yard Cogeneration Partners L P & F01 Second Street 6500 & Fort Greely & AK & 11205 \\
\hline
\end{tabular}




\section{Appendix F: Feasibility Analysis for CHP}

\section{Obtain Site Data:}

Gathering site data is a critical phase of a 'Technical and Economic Feasibility Assessment' for a CHP plant. This allows for accurate assessment of savings potential without going through all the rigorous design steps; thus reducing up front costs and still providing the site with an accurate estimate of project costs and potential energy (and energy cost) savings.

\section{Collecting Utility Data}

- Copies of utility bills for past two years (both Gas and Electric). This data provides insight into total energy usage and can help build energy use profiles prior to the Technical Feasibility Assessment Phase

- Develop demand and energy use profiles. Knowing the demand and energy use profiles allows for better determination of the potential size of the CHP plant and what size equipment should be reviewed. Also helps to determine the kind of power generation equipment (i.e., Turbine, engine, microturbine, fuel cell, etc.)

- Develop customer specific information concerning utility interconnection. Does the customer require parallel grid or stand alone operation. What switchgear is required?

- Evaluate the impact of purchasing back-up power from the utility. In some cases the backup power is more expensive than adding extra (or redundant) generation capacity. This must be determined prior to developing capital cost estimates.

\section{CHP System Data}

- The first step is to determine the estimated size of the proposed CHP system. This requires a good understanding of the customer's energy use profile.

- In many cases the required size of the CHP plant will allow the designer to develop multiple options. These options will consider the number of generators and the sizes required.

- Once the appropriate technology has been identified, specific manufacturer's equipment needs to be selected and reviewed. The appropriate selection depends 
on the size of the system and the cost of the equipment. It is recommended that quotations from at least two manufacturers should be obtained.

- In obtaining the quotation, the following information should be obtained:

$>$ Price of the generator: The price for all quotations should be based on the same build specification. This is important since manufacturers often use a different specification of standard components.

$>$ Performance Specification: The actual performance of the equipment is critical to comparing equipment. All performance data should be developed using comparable conditions and fuel composition. The designer needs to know the full load rating of the generator when the unit is used in a prime power or continuous duty application.

$>$ Heat Balance of the Generator: If the generator is going to be part of a CHP system, knowing the heat balance of the engine or turbine is critical.

$>$ Service Contract Cost: The cost of system maintenance will impact the economics of a CHP proposal. It is necessary to get a firm quote for the cost of maintenance and a description of what is covered. Many times the quotations used only cover routine maintenance and the customer is expecting complete coverage (routine, scheduled and unscheduled events).

- Determine how the waste heat from the generator will be used..

- Determine if the waste heat recovery can always be utilized.

\section{Company Data}

- The information obtained concerning how the company currently purchases energy and capitalizes projects is very important to understand. Often times the required "Return on Investment (ROI)" is crucial to determining whether a CHP project makes economic sense. All companies use a different ROI criteria

- Since the utility data does not always provide complete information on how a customer uses energy, it is important to get the customer to assist the designer in gaining insight into the various energy loads. It is especially important to fully understand how the waste heat from the generation equipment will be used. In many cases the generators will run at part load, thus reducing the amount of waste heat that is available.

- The designer must also determine the most cost-effective approach to delivering the electricity to the customer. Obtaining a one-line drawing of the electric service entering the customer's facility is an easy way to determine size of existing transformers, voltage of service, and type of switchgear already present.

- The designer must obtain information concerning siting of equipment. Gaining an understanding of the customers requirements for siting the equipment and the 
relationship between where the generators are located and where the waste heat will be used is critical.

\section{Further Investigation Warranted}

- Prior to continuing into the Technical Feasibility Phase, the designer must perform a quick check to see if the project makes sense. The data collected should be sufficient to determine if the energy cost savings is enough to justify further investigation.

- A "YES" or "NO" decision should be made before proceeding to the next phase of the assessment 


\section{Technical Feasibility Assessment:}

\section{With a "Yes" decision, it is time to move into the Technical Feasibility Assessment phase. During this phase the designer will fine-tune the selection of equipment that will be used as part of the cogeneration plant.}

\section{Identifying Sizing Options and Operating Modes}

- Since different vendors offer different sizes of equipment, it is time to determine the sizes for each piece of equipment. The size of the generator, engine radiator or cooling tower, heat recovery components, and use of the waste heat must be determined. If the cogen plant will incorporate a cooling option, the size of the absorption chiller must all be determined since this will impact the heat recovery component selection and cooling tower size.

- In parallel to determining the size of all key equipment, the designer must determine the various operating modes that the system will encounter. It is extremely important to understand the electric load profile on a 24 hour / 7 days a week basis. It is also important to determine how the customer will use the waste heat from the generator plant. This combination of the electric load profile and how the waste heat will be used is key to sizing the generator plant, determining the number of generators to be used and whether the use of exhaust gas heat recovery is justified.

- The above information will feed into the next step.

2. Develop CHP System Conceptual Design

- With final selection of equipment and operating modes known, the designer can begin developing the conceptual system design.

- The designer should start by obtaining a one-line diagram for the electrical circuit currently in use by the customer. This allows the designer to determine what electrical components are required to interface the generator with the customer circuit. It will also be used to identify the required voltage for the generator or if any additional transformers and switchgear is required. This will be particularly important for those systems that parallel with the utility.

- After developing the generation portion of the Conceptual System, the designer must determine the most practical use of the waste heat. This decision should have been made during the Technical Feasibility Assessment phase.

- Figure 1 shows a simplified version of a typical cogeneration plant that uses the generator waste heat to drive a single stage absorption chiller. Even in this simplified design, it is important to know a variety of flows and temperatures. 


\section{Figure 1 \\ Sample CHP Conceptual Design}

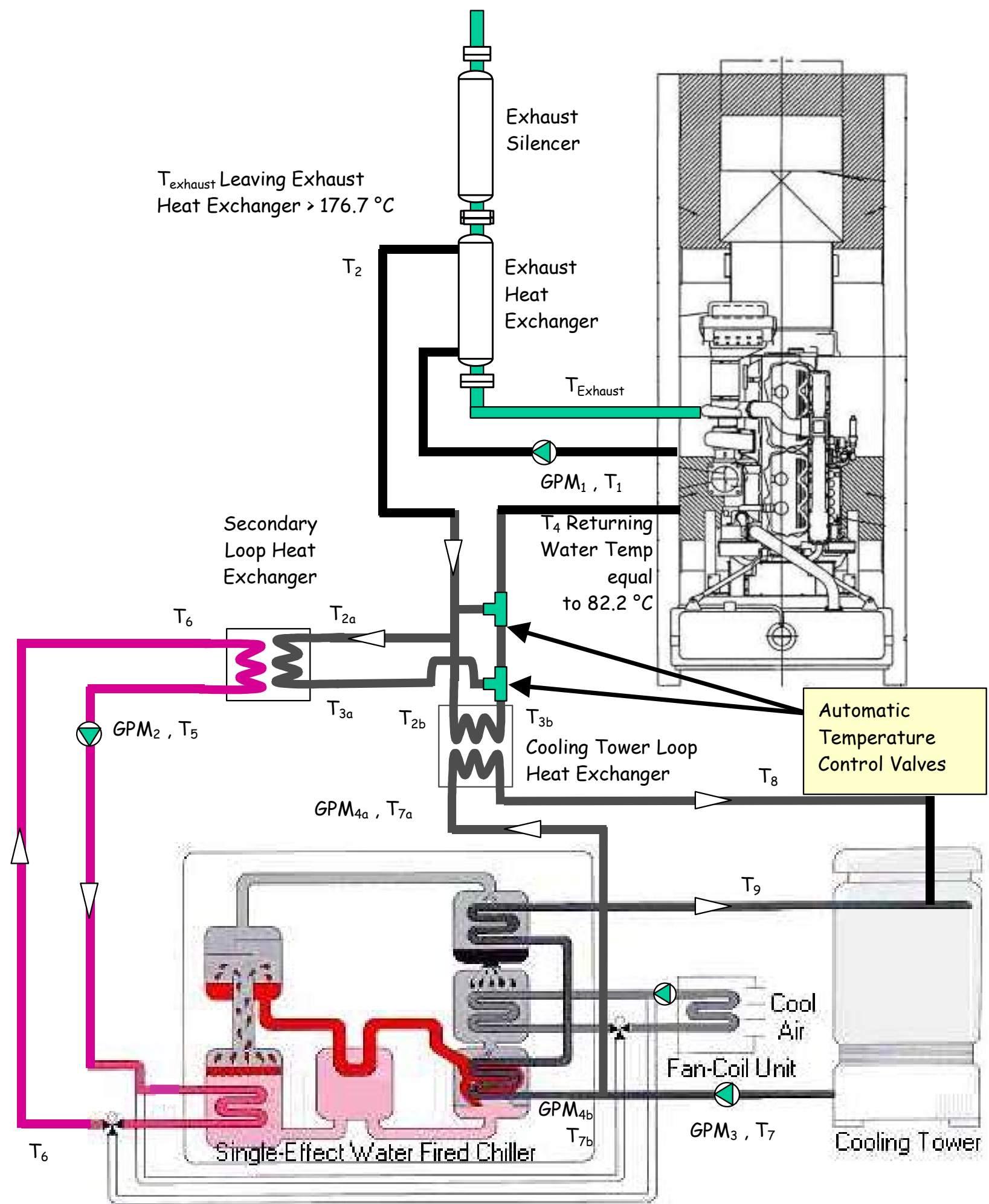


Flows and Temperatures that must be determined for all operating modes

\section{$\underline{\text { Temperatures }}$}

$\mathrm{T}_{1}$ - Leaving Engine Coolant Temperature

$\mathrm{T}_{2}$ - Leaving Exhaust Heat Exchanger Coolant Temperature

$\mathrm{T}_{2 \mathrm{a}}$ - Entering Secondary Loop Heat Exchanger Coolant Temperature (Primary Side)

$\mathrm{T}_{2 \mathrm{~b}}$ - Entering Cooling Tower Loop Heat Exchanger Coolant Temperature (Primary

Side)

$\mathrm{T}_{3 \mathrm{a}}$ - Leaving Secondary Loop Heat Exchanger Coolant Temperature (Primary Side)

$\mathrm{T}_{3 \mathrm{~b}}$ - Leaving Cooling Tower Loop Heat Exchanger Coolant Temperature (Primary Side)

$\mathrm{T}_{4}$ - Entering Engine Coolant Temperature (Should be $82.2^{\circ} \mathrm{C}$ )

$\mathrm{T}_{5}$ - Leaving Secondary Loop Heat Exchanger Water Temperature (Secondary Side) and

Entering Absorber Generator Water Temperature

$\mathrm{T}_{6}$ - Leaving Absorber Generator Water Temperature and Entering Secondary Loop

Heat Exchanger Water Temperature (Secondary Side)

$\mathrm{T}_{7 \mathrm{a}}$ - Entering Cooling Tower Loop Heat Exchanger Water Temperature (Secondary Side)

$\mathrm{T}_{7 \mathrm{~b}}$ - Entering Absorber Condenser Water Temperature

$\mathrm{T}_{8}$ - Leaving Cooling Tower Loop Heat Exchanger Water Temperature (Secondary Side)

$\mathrm{T}_{9}$ - Leaving Absorber Condenser Water Temperature

$\mathrm{T}_{\text {exhaust }}$ - Exhaust Temperature Leaving Engine and Entering Exhaust Heat Exchanger

$\mathrm{T}_{\text {exhaust }}$ Leaving - Exhaust Temperature Leaving Exhaust Heat Exchanger (Must be

Greater than $176.7^{\circ} \mathrm{C}$ )

\section{Flow Rates}

$\mathrm{GPM}_{1}$ - Engine Coolant Circuit Flow Rate

$\mathrm{GPM}_{2}-$ Absorber Generator (Secondary Loop) Flow Rate

$\mathrm{GPM}_{3}$ - Cooling Tower Flow Rate

$\mathrm{GPM}_{4 \mathrm{a}}$ - Cooling Tower Loop Heat Exchanger Flow Rate

$\mathrm{GPM}_{4 b}$ - Absorber Condenser Flow Rate

Note: Flow Rates $\mathrm{GPM}_{4 \mathrm{a}}$ and $\mathrm{GPM}_{4 \mathrm{~b}}$ equals Flow Rate $\mathrm{GPM}_{3}$ 


\section{Economic Feasibility Assessment:}

Once the Conceptual System Design is complete, the designer must evaluate the economic potential of the design. During this phase, the designer will continue to fine tune the conceptual design as well as evaluate alternative concepts that could be utilized. The goal of this phase is to gain a full understanding of the energy and ownership economics of the proposed CHP design.

1. Compare Cost Estimates for the proposed CHP System Against Alternative Options

- With the conceptual design for the CHP system complete, the designer can develop a cost estimate for all required equipment. This should should include the generator, electric switchgear, all heat exchangers, single stage absorption chiller (if used), pumps, cooling towers, etc. The cost estimate for operation and maintenance should also be developed.

- In a parallel path to developing the Conceptual System Design, all alternatives that may be applicable need to be developed through the point of developing a cost estimate.

- Once the cost estimates of all options are complete, the designer can conduct a economic comparison of the various systems can be completed.

2. Further Investigation Warranted

- Prior to evaluating financing or ownership options, the designer must analyze the economic benefits of the Conceptual System Design to see if the project still makes sense. At this point, the designer still has not performed the detailed engineering to install the CHP System, but has enough detail to make a final determination of the viability of the project.

- A "YES" or "NO" decision should be made before proceeding.

- A "YES" response warrants further discussion with client to determine the best way to capitalize the project.

- A "NO" response ends the review of the project 


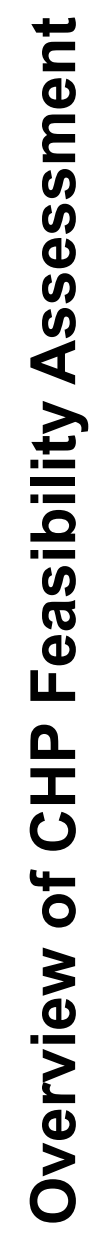

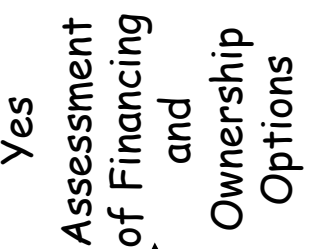

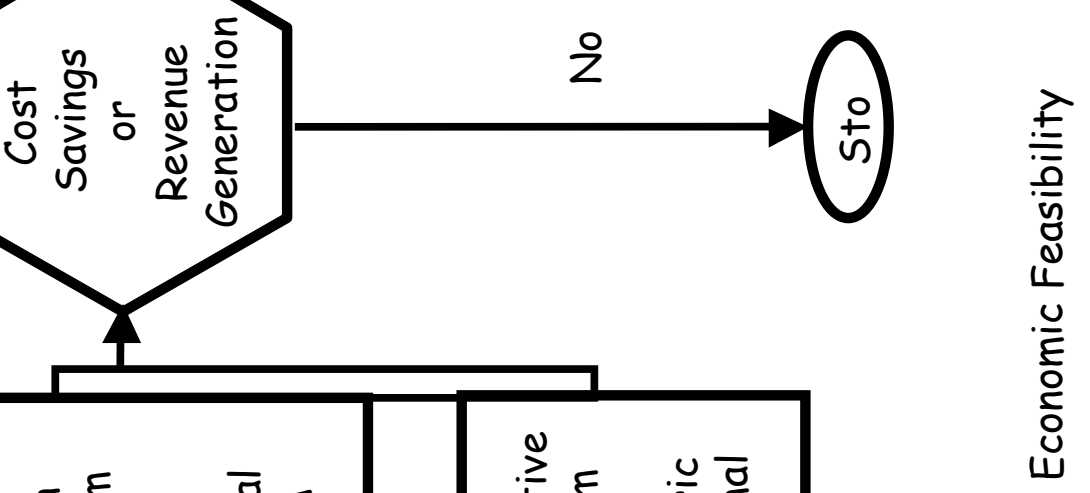

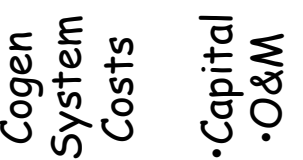

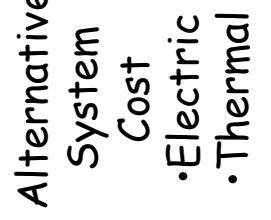
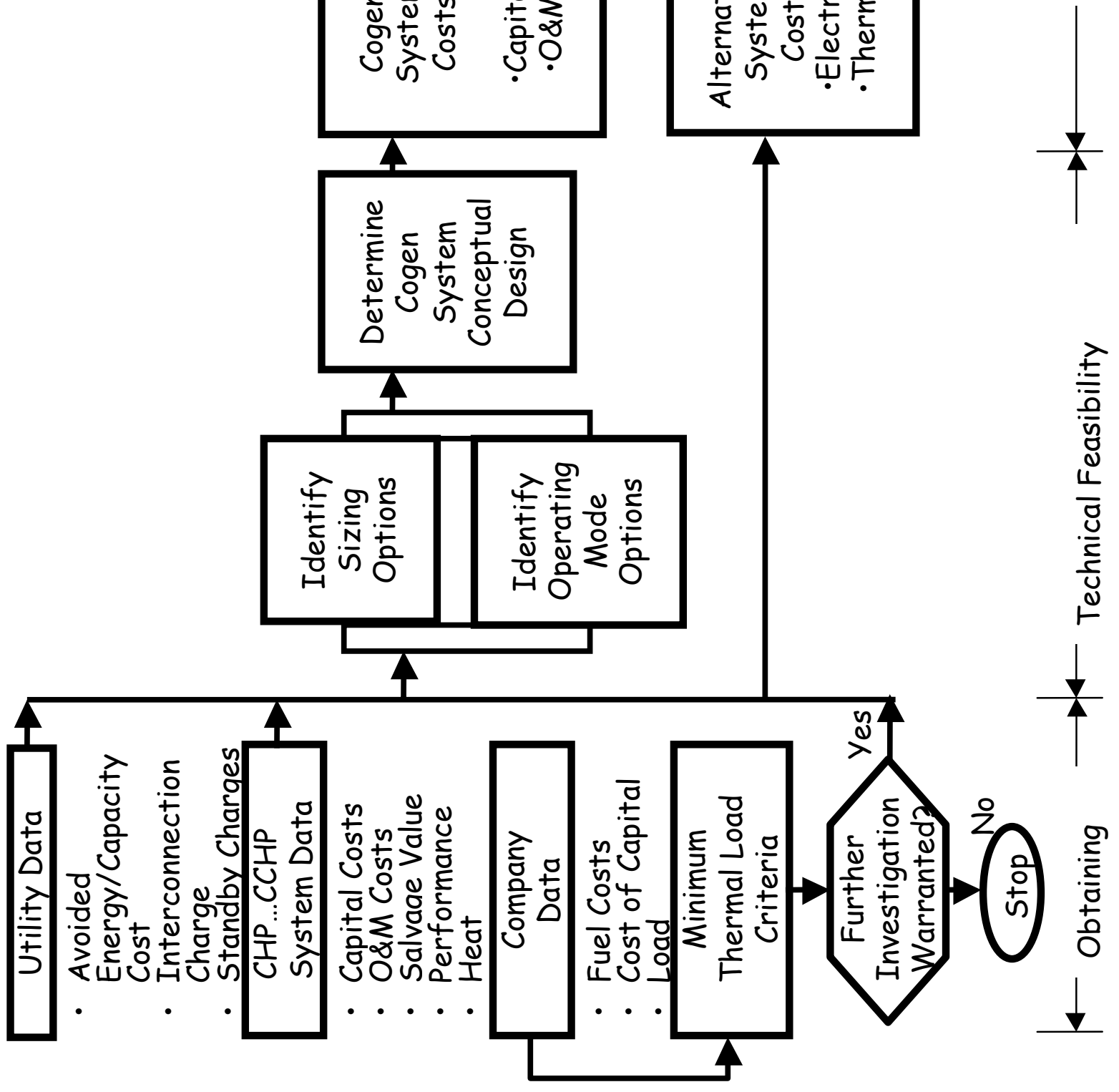